Ting ji

\title{
Aggregate implications of occupational inheritance in China and India
}

\author{
${ }^{1}$ School of International Trade and Economics, Central University of Finance and Economics, 39 South College Road, Haidian \\ District, Beijing 100081, China, E-mail: jiting@cufe.edu.cn
}

\begin{abstract}
:
This paper documents occupational inheritance - that is, children's inheritance of their parents' occupations - in China, India, and other countries. Among the causes of the prevalence of occupational inheritance, we target two broad categories that impede growth: labor market frictions and barriers to human capital acquisition. Counterfactual experiments based on a tractable occupational choice model suggest that if the impediments mentioned above were reduced to the US levels, labor productivity would grow by 60-75\% in China and $107-178 \%$ in India. China realized $74-89 \%$ of this growth potential from the 1980 s to 2009 . In addition, this productivity gain is accompanied by a decrease in the correlation of intergenerational incomes.
\end{abstract}

Keywords: human capital, intergenerational income mobility, intergenerational occupational mobility, labor productivity, occupational inheritance

JEL classification: O11, O4, E24, J24

DOI: $10.1515 /$ bejm-2018-0030

\section{Introduction}

Occupational inheritance - that is, children's inheritance of their parents' occupations and, more broadly, their occupation status - is very common in many developing countries, such as China and India. Sociologists and economists have carried out extensive comparative research on intergenerational occupational transition patterns. ${ }^{1}$ However, the existing literature places a particular focus on establishing empirical facts and examining their implications for inequality, and it targets mostly developed countries. ${ }^{2}$ I this paper, we aim to discuss occupational inheritance's implications on efficiency, i.e. productivity, in developing countries from a macroeconomic perspective. We first document systematic patterns of occupational inheritance across countries and then show through quantitative exercises that forces that create occupational inheritance have also generated significant cross-country differences in per capita output. Our underlying logic is that occupations are linked with specific skill contents, and therefore, the observed patterns of occupational choices also reflect frictions and barriers that impede the accumulation and allocation of occupation-related skills and depress aggregate productivity.

We first establish cross-country observations for intergenerational occupational transition, and more specifically, we correlate occupational inheritance and income level. We use two measures, the IOM rate and the Altham statistic, ${ }^{3}$ to depict occupational inheritance. According to our findings, workers in poor countries are less likely to pursue careers outside their parents' occupations, which suggests that in order to start a career in an occupation in which no senior family members have any experience or influence, one must overcome obstacles much greater than those faced by his or her counterparts in developed countries. These obstacles may have different sources, and we classify them into three main categories based on how they can affect the macroeconomy: labor market frictions, barriers to acquiring human capital, and the economic structure.

Labor market frictions result in the inefficient allocation of human talent. For example, in China, household registration ("hukou" ) ties rural families to agricultural work. In India, the caste system categorizes people into different occupations in specific castes and limits occupational choices, again perpetuating occupational inheritance.

Additionally, Chinese and Indian workers face larger barriers to human capital acquisition than their US counterparts do. China and India lag behind the US in terms of average educational attainment. Meanwhile, poor contract enforcement and binding financial constraints in China and India hinder workplace training. As a result, workers in China and India are forced to refer to senior family members for help, resulting in occupational inheritance. 
The last channel is the economic structure. Occupations differ in terms of the prevalence of occupational inheritance. For certain occupations, skills are more likely to be passed down within a family, or alternatively, innate talent can be more easily transmitted from parents to children. ${ }^{4}$ If an economy is composed of occupations for which occupational inheritance occurs frequently, occupational inheritance would prevail in this economy. Because it is rooted in the nature of an economy, this channel is not considered a target in our quantitative exercises, and we will exclude its effects.

The above observations lead to our second contribution. We quantify the aggregate effects of occupational inheritance on per capita output, which provides a new perspective on the cross-country productivity gap. We use the tractable occupational choice framework from Hsieh, Hurst, Jones, and Klenow (2013, HHJK hereafter), which had its roots in Roy (1951) and Eaton and Kortum (2002). In this framework, the quality of labor is a combination of innate talent and acquired human capital, with barriers to acquiring human capital and frictions in allocating labor. Heterogeneous individuals choose their optimal occupations based on their talent draw and frictions in the labor market, which determine aggregate productivity. Applying this framework to the US economy from 1960 to 2010, HHJK find that approximately one-quarter of the growth in this period can be attributed to the improved allocation of women and African-Americans in the labor market.

Our quantitative results suggest that if the barriers to intergenerational occupational mobility were reduced to the US levels, labor productivity would grow by $60-75 \%$ in China and $107-178 \%$ in India. In addition, China realized $74-89 \%$ of this growth potential from the 1980s to 2009, which indicates that while China has made great progress during this period, it must also find other sources for sustainable growth going forward. Meanwhile, this productivity growth is are associated with a decrease in intergenerational income correlation.

There is a burgeoning literature using similar framework as in HHJK. Lagakos and Waugh (2013) use selection to explain the enormous cross-country differences in agricultural productivity. Cortes and Gallipoli (2014) evaluate the aggregate costs of occupational mobility in the US, using the Dictionary of Occupational Titles to measure occupation characteristics. Jung (2014) develops a tractable endogenous growth model in which growth occurs as a result of a better match between tasks and human talent. The most similar study to this paper is Sinha (2014), which also documents high occupational persistence in poor countries but emphasizes the role of financial constraints in inadequate human capital acquisition when discussing the implications for labor productivity. ${ }^{5}$

This paper is related to the literature that studies human capital accumulation with theoretical models and quantitative exercises. Related to the nature-versus-nurture decomposition in the empirical literature, Restuccia and Urrutia (2004) establish a model that incorporates innate talent, early education, and college education as sources of human capital. They find that investment in education, especially early education, can account for approximately one-half of the intergenerational earnings persistence, and their model offers rich education policy implications. Erosa, Koreshkova, and Restuccia (2010) develop a heterogeneous agent model that incorporates born ability and acquired skill by education investment and find that human capital accumulation significantly amplifies TFP differences across countries. Additionally, Córdoba and Ripoll (2013) provide a model studying the formation of human capital and finds that frictions such as credit constraints, access to public education, fertility and mortality are important in creating schooling differences across countries, which further generates productivity gaps. Manuelli and Seshadri (2014) endogenizes the quality of human capital, which significantly amplifies the elasticity of output with respect to TFP. However, these papers address mainly human capital accumulation but remain silent on the allocation of talent, which is a topic our paper intends to investigate.

A strand of research focuses on the role of factor input misallocation in creating low measured TFP, in which Restuccia and Rogerson (2013) provide an extensive survey. In a seminal paper, Hsieh and Klenow (2009) argue that misallocation of capital and labor among different plants leads to TFP loss in China and India. Reducing firm-level misallocation to the US level would result in 30-50\% growth in China's manufacturing TFP and a 40-60\% growth in India's. Our paper indicates that occupational inheritance would lead to an even larger loss in productivity than capital and labor misallocation at the firm level. Adamopoulos et al. (2017) study the effect of misallocation and selection on agricultural productivity by taking advantage of panel data and quantitative analysis based on a two-sector (agriculture-non-agriculture) model, and they find that the misallocation of capital and labor generates large productivity losses and that the selection of workers into different sectors would further amplify this loss. Our paper complements their paper in the sense that we investigate all occupations rather than limiting our study to farming and agriculture.

Cavalcanti and Santos (2015) is a closely related paper investigating misallocation of human resources. They study the macroeconomic implications of earnings differentials between the public and private sectors using an occupational choice model with the life cycle. The public sector earnings premium would possibly induce highly productive workers to civil services and thus hurt employment and entrepreneurship in private sectors, which creates economy-wide productivity losses. They find that a reasonable reform of closing the earnings gap would generate a sizable increase in the aggregate output in Brazil. Our paper complements to their paper by discussing a different distortion in occupational choices that also leads to human resource misallocation. 
The distortion in our paper is group-occupation specific and determined jointly by an individual's family background and her occupation, while in their paper the distortion is specific to the public sector (but theoretically it could also be extended to be individual characteristics dependent as well).

It is interesting to understand the interaction of the two types of distortions. Therefore, we extend our model to allow for a source of distortion for the public-private wage premium as well in the Section 5.5. An illustrative analysis on the extended version of our model suggests that this new distortion could either attenuate or aggravate the impacts of the barriers to occupational choices on productivity in our model, depending on detailed quantitative properties of the misallocations. We implement a quantitative analysis on China, and we find for this particular case the distortion that creates the public sector earnings aggravates the negative effects of the distortions on occupational choices on productivity, but the magnitude of such interaction is relatively limited.

The rest of the paper proceeds as follows. We present empirical findings and background information on labor market frictions and human capital accumulation in China and India in Section 2. Section 3 describes the intergenerational occupational choice model. We discuss the data and parameterization procedures in Section 4 and implement quantitative exercises in Section 5. In Section 6, we conclude.

\section{Motivating facts and background information}

This section presents the observations and background information that motivate the paper. First, we present the significant correlation between IOM rates and GDP per capita. Meanwhile, we also investigate whether these results are robust to different specifications and measurements. Second, we report the relationship between Altham statistics and income levels across countries. In the final subsection, we provide background information on labor market frictions and barriers to human capital accumulation in China and India.

Before discussing additional details, it is worth introducing the International Standard Classification of Occupations (ISCO). Occupations that feature the same name could actually have different natures in different countries. In order to overcome such obstacles to comparative research, researchers created the ISCO, which is a systematical classification of occupations that is consistent across countries. The ISCO is currently maintained by the International Labor Organization, and its mostly widely used version is the ISCO88. The ISCO88 has a hierarchical structure with 10 major groups (1-digit level), 28 sub-major groups (2-digit level), 116 minor groups (3-digit level), and 390 unit groups (4-digit level). All the data we use in this paper follow the ISCO88, which allows for cross-country comparison.

In this section, we use mainly data from the International Social Survey Programme (ISSP) 2009 (ISSP Research Group 2009), which covers 54,733 individuals in 40 countries and territories in total. ISSP is an annual program of cross-country surveys on various topics of social science research, and the topic of the ISSP 2009 was social inequality; thereby, it provides helpful information for our research, and the data fit our interests quite well for several reasons. First, as previously mentioned, the ISSP 2009 uses the ISCO 88 as the classification system of occupations for all countries. Second, it provides a great deal of relevant information, such as the respondent's occupation and the respondent's father's occupation. It is worth mentioning that in the ISSP 2009 , the question related to the respondent's father was, "When you were $<14-15-16>$ years old, what kind of work did your father do?" The framing of the survey question, "When you were $<14-15-16>$ years old," is helpful because it restricts information on the respondent's father's occupation to a narrowly defined prime age. Third, it provides both the respondent's first occupation and his or her current occupation, providing an intrinsic opportunity to double check whether these responses match. Fourth, as the name suggests, the field work of the ISSP 2009 was carried out around the year $2009^{6}$ in all participating countries, which removes time variation and makes the data more comparable across countries.

Unfortunately, the ISSP 2009 data do not include India. Although it is not necessary to include India when establishing a general pattern among developing countries, we still hope to keep India in both the empirical portion and the quantitative exercise portion of the paper for comparison. In order to include India in our analysis, we use data from the IPUMS International (Minnesota Population Center 2014). The IPUMS International collects and harmonizes census data from across the world, and we can obtain access to the Indian Employment Survey for 1993, 1999, and 2004. In fact, the IPUMS International data also provide additional information for China, and therefore, we also use China's 1982 and 1990 Censuses for observations at additional time points. The Indian Employment Surveys include 564,740 observations in 1993, 596,688 observations in 1999, and 602,833 observations in 2004, while both Chinese Censuses in 1982 and 1990 interviewed 1\% of the population, creating 10,039,191 observations in 1982 and 11,835,947 observations in 1990. The IPUMS International harmonizes the classification of occupations according to the ISCO88, but it provides only 1-digit-level occupation codes, which is usually due to the limitations of occupation information in source countries' original data. In addition, the IPUMS International data provide only the respondents' current occupations. 
Our quantitative results in later sections are restricted to the intergenerational occupational transition between fathers and sons, which requires a similar treatment in this empirical section to main consistency. The reasons for this choice are the following: (1) existing empirical research deals predominantly with the intergenerational occupational transition between fathers and sons, and much less is known about the role of mothers in the process of children's occupational choice. Therefore, we lack information of the role of mothers in the family decisions related to children's occupational choices; and (2) males' labor force participation rates are usually higher than those of females, especially for some developing countries, and a large portion of females quit the labor market after marriage. Home production would have very different implications for different families, and since we do not want to introduce this further noise, we choose not to include girls in the analysis. In making this choice, we do not mean to understate the importance of females in an economy, but rather, we must make a compromise due to limited existing knowledge and information. However, the empirical patterns in this section still hold when including all girls in the analysis. Similarly, if the influence of parents on girls' occupational choices are similar to that on boys' choices, the conclusion in the later quantitative exercises would also remain unchanged.

\subsection{IOM rates vs. GDP per capita}

In this section, we use the IOM rate as an indicator of intergenerational occupational mobility. By definition, the IOM rate is the proportion of children that choose an occupation that is different from that of their fathers. As the IOM rate increases, the degree of occupational inheritance decreases. First, denote by $\pi^{L}=\left(\pi_{1}^{L}, \pi_{2}^{L}, \ldots \pi_{M}^{L}\right)$ the distribution of fathers' occupations. In addition, $P=\left[p_{i j}\right]_{M \times M}$ denotes the intergenerational occupational transition matrix, where row $i$ corresponds to fathers' occupations and column $j$ corresponds to sons' occupations; $p_{i j}$ is the possibility of a worker choosing occupation $j$, conditional on the fact that his father works in occupation $i$. Therefore, diagonal elements of the transition matrix, $p_{i i}$, represent the possibility of occupational inheritance for children with father working in occupation $i$. The IOM rate is then calculated as

$$
\operatorname{IOM}=1-\pi^{L} \cdot \operatorname{diag}(P)
$$

where $\operatorname{diag}(P)=\left(p_{11}, p_{22}, \ldots, p_{M M}\right)$ is the vector of all diagonal elements of the transition matrix $P$.

It is usually more convenient to think about the percentage of sons that inherit their fathers' occupations, i.e. $(1-I O M)$, and therefore, Equation (1) can be re-written as

$$
1-\operatorname{IOM}=\pi^{L} \cdot \operatorname{diag}(P)
$$

Equation (2) suggests that $(1-I O M)$ is equal to the summation of the probabilities of all children inheriting their father's occupations and can be called the Intergenerational Occupational Inheritance (IOI) rate for convenience. The IOI rate is a complement to the IOM rate, and they sum to 1 . As the IOI rate increases, the degree of occupational inheritance increases.

A

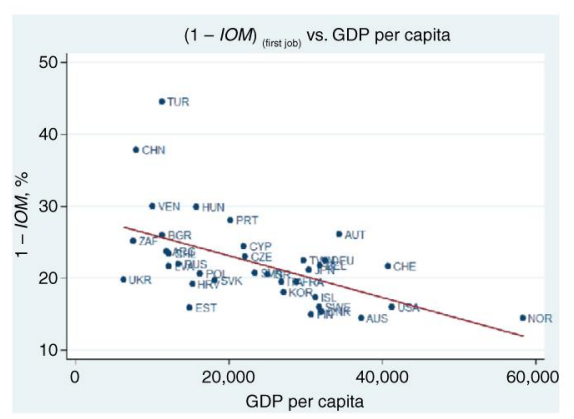

B

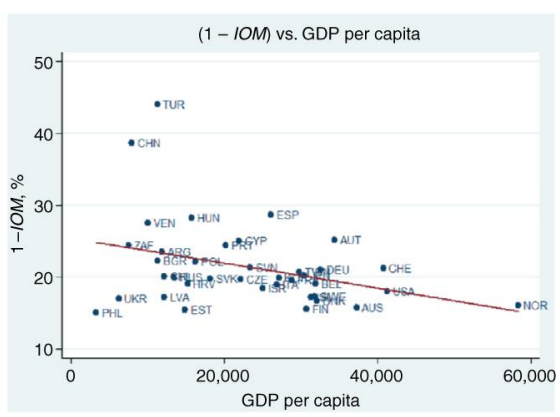

Figure 1: $(1-I O M)$ vs. GDP per capita. (A) First Occupation; (B) Current Occupation.

We first calculate $(1-I O M)$ based on the respondent's first occupation, ${ }^{7}$ and then repeat the same procedures using the respondent's current occupation. Figure 1 presents the correlation between $(1-I O M)$ and real GDP per capita based on these two different specifications. Both graphs report a significant correlation between $(1-I O M)$ and GDP per capita; the slopes of the linear fitted line are reported in the first two rows of Table 1. According to the first row of this table, the slope for Figure $1 \mathrm{~A}$ is $-2.90 \cdot 10^{-4}$, which implies that if the GDP 
per capita differs by $\$ 40,000$ between two countries, the IOM rates should differ by $11.6 \%$. In the second row of the table, the slope for Figure $1 \mathrm{~B}$ is $-1.75 \cdot 10^{-4}$ and statistically significant. Comparing these two figures, the GDP per capita correlation for the IOM rate based on the first occupation is larger than the correlation for the IOM rate based on the current occupation. Our quantitative exercises will be based on the current occupation, and therefore, our estimates provide a lower bound for the potential gains from removing barriers to IOM for China and India.

Table 1: Regression results.

\begin{tabular}{llrr}
\hline & & Coefficient & t statistic \\
\hline IOM rates & First occupation & $-2.90 \mathrm{e}-04$ & -3.75 \\
& Current occupation & $-1.75 \mathrm{e}-04$ & -2.21 \\
& First occupation (w/o Farmers) & $-2.53 \mathrm{e}-04$ & -3.39 \\
\multirow{3}{*}{ Altham statistics } & Current occupation (w/o Farmers) & $-1.27 \mathrm{e}-04$ & -1.75 \\
& First occupation & $-3.13 \mathrm{e}-04$ & -1.55 \\
& Current occupation & $-1.95 \mathrm{e}-04$ & -0.97 \\
\hline
\end{tabular}

As previously mentioned, the ISSP 2009 data do not include India. In order to include India, we simply calculate $(1-I O M)$ from the IPUMS International data and put all the data points on top of Figure $1 \mathrm{~B}$ and produce Figure 5 in Appendix C. The IPUMS International data provide five extra data points: China in 1982 and 1990, and India in 1993, 1999, and 2004. It can be seen that these observations all display very high (1 $I O M)$ rates, which suggests that $(1-I O M)$ decreased dramatically for China from the 1980s to 2009. Since these five extra data points are from a different dataset, we do not include them when calculating the correlation between $(1-I O M)$ and GDP per capita in Table 1 to prevent strong outlier effects.

It might be a concern that farmers, as the majority of the labor force in many developing countries, will completely dominate the results. If sons of farmers are also more likely to be farmers and the labor force is composed predominantly of farmers, the correlation between $(1-I O M)$ and GDP per capita would be significant even if there is no inheritance of other occupations. Of course, the barriers that impede sons of farmers from moving to new occupations also fits our topic, but if that is the case, a simpler analysis considering only farmers and non-farmers, similar to Adamopoulos et al. (2017), would serve not only the agricultural sector but also the whole economy. Therefore, we would like to know the extent to which farmers drive these results. We investigate this issue by removing all farmers from the data and reproducing the results. The graphs appear the same, with similarly significant and negative slopes, but on a smaller magnitude, which can been seen in Figure 3 and Figure 4 in Appendix $C$ and in Table 1. Farmers explain part of the occupational inheritance phenomenon, but much remains to be explained by all other occupations.

\subsection{Altham statistics vs. GDP per capita}

The IOM rate includes information on the distribution of fathers' occupations and the diagonal elements of the intergenerational occupational transition matrix; therefore, alone, it cannot disentangle interaction from prevalence, as discussed in Long and Ferrie (2013). Prevalence refers to the difference arising from fathers' occupational distribution, while interaction refers to the conditional probability that sons will switch to occupations that are different from their fathers' occupations. The problem of farmers in the previous subsection also involves excluding the effect of prevalence from interaction. Although both effects fit our topic, we follow Long and Ferrie (2013) to further explore empirical facts.

The interaction effect is determined by the intergenerational occupational transition matrix. In order to directly analyze the properties of the transition matrix, Long and Ferrie (2013) propose using the Altham statistic. For any two matrices $P=\left\{p_{i j}\right\}_{r \times s}$ and $Q=\left\{q_{i j}\right\}_{r \times s}$, the Altham statistic is defined as

$$
d(P, Q)=\left[\sum_{i=1}^{r} \sum_{j=1}^{s} \sum_{l=1}^{r} \sum_{m=1}^{s}\left|\log \left(\frac{p_{i j} p_{l m} q_{i m} q_{l j}}{p_{i m} p_{l j} q_{i j} q_{l m}}\right)\right|^{2}\right]^{\frac{1}{2}}
$$

The Altham statistic $d(P, Q)$ represents the distance between the row-column associations between matrices $P$ and $Q$. In our case, $P$ is the transition matrix for each country, and $Q$ is the benchmark matrix, i.e. a matrix with all elements set at 1 . The economic interpretation of $Q$ is that children from any type of family will have an equal opportunity to enter any occupation. In addition, here, $r=s$ because the transition matrix is square. 
To further understand the mathematical implications of the Altham statistic, we would like to transform equation (3) into a more straightforward form. Define $a_{i j}=\log \left(\frac{p_{i j}}{\bar{q}_{i j}}\right)$. Following some derivations as shown in Appendix B, we re-write Equation (3) as

$$
\begin{aligned}
& d(P, Q)^{2}= \\
& 4 r s \cdot \sum_{i} \sum_{j}[a_{i j}-\underbrace{\frac{\sum_{m} \sum_{l} a_{m l}}{r s}}_{\text {matrix mean }}-\underbrace{\left(\frac{\sum_{m} a_{m j}}{r}-\frac{\sum_{m} \sum_{l} a_{m l}}{r s}\right)}_{\text {column deviation }}-\underbrace{\left(\frac{\sum_{l} a_{i l}}{s}-\frac{\sum_{m} \sum_{l} a_{m l}}{r s}\right)}_{\text {row deviation }}]^{2}
\end{aligned}
$$

According to Equation (4), the items at the core of the equation are $a_{i j}$ - matrix mean - column deviation row deviation $=$ residual. That is, $d(P, Q)^{2}$ is a sum of squares of the residual of the matrix $\left\{a_{i j}\right\}$. In other words, the Altham statistic $d(P, Q)^{2}$ is the F test statistic of a two-way analysis of variance (ANOVA) between the transition matrix $P$ and the benchmark matrix $Q$. The two-way ANOVA F statistic can detect the interaction effects between the row variable and the column variable. By calculating $d(P, Q)$, we know the extent to which the rows and columns of $P$ are associated. Following a simple calculation, one can find that $d(Q, Q)=0$. That is, we should find a smaller $d(P, Q)$ for countries in which sons are relatively freer to deviate from their fathers' occupations.

We present the relationship between Altham statistics and GDP per capita in Figure 2. Again, the two subfigures are based on respondents' first occupations and current occupations, respectively. As before, we also use data from IPUMS International to calculate Altham statistics for China in 1982/1990 and India in 1993/1999/2004, and they appear in red in Figure 6. The slopes of the regression lines are listed in Table 1.

A

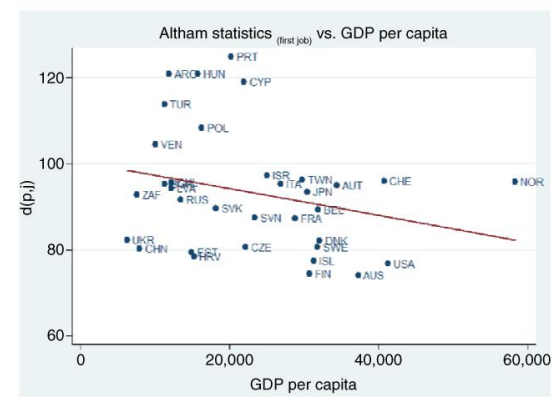

B

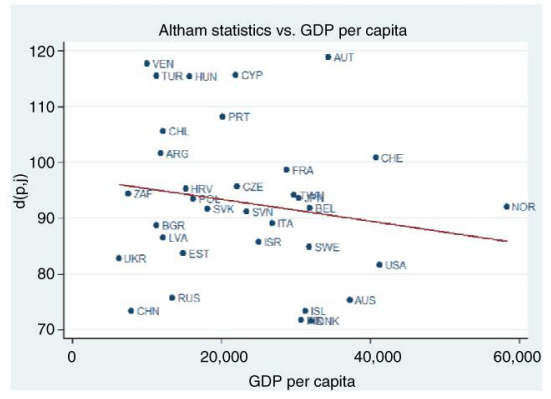

Figure 2: Altham statistics vs. GDP per capita. (A) First Occupation; (B) Current Occupation.

According to Figure 2, the correlation between Altham statistics and GDP per capita is negative but on the margin of being significant $(t=-1.55)$, which suggests that interaction is not the only determinant of differences in IOM rates between different countries. That is, both the the distribution of fathers' occupations $\pi^{L}$ and the intergenerational occupational transition matrix $P$ play a role in determining occupational inheritance levels. Moreover, compared with China, India shows very high Altham statistics in multiple years. This result implies that, regardless of their family background, workers in India will always find it very difficult to transfer from their fathers' occupations to new occupations. This finding partly explains why, in our counterfactual experiment, the effect of reducing barriers in India is much larger than that in China.

\subsection{China and India}

In this section, we discuss our countries of interest, China and India, in detail. We first explain why we target China and India and then introduce some background information on labor market frictions and barriers to human capital accumulation in China and India.

\subsubsection{Why China and India?}

In this paper, we focus on China and India, although occupational inheritance is a global phenomenon that affects many developing countries. We choose China and India for several reasons. First, both China and India are large developing countries that are often compared with the US. Thus, we do not need to be concerned about problems such as economy of scales and extreme occupation distributions. Second, both China and India are populous countries such that a low productivity problem in these countries has great implications for global 
poverty. Third, the comparison between China and India is very interesting in itself. Both countries have a very long history and have developed very unique socioeconomic conventions that have important implications for occupational inheritance. As discussed in Section 2.1, India shows very high Altham statistics, while the overall IOM rate in China is slightly higher than that in India. All these elements in the occupational inheritance phenomenon lead to a much larger productivity loss in India than in China. Finally, we focus on China and India in order to make our results comparable to those of Hsieh and Klenow (2009). Our results suggest that occupational inheritance is an even greater problem in China and India than factor input misallocation at the firm level.

\subsubsection{Labor market frictions in China and India}

Labor market frictions result in the inefficient allocation of human talent, which hurts aggregate productivity. In China, major sources of labor market frictions are "hukou" and "guanxi," while in India, the caste system restricts occupational choices.

The "hukou" system officially registers each individual's information, such as his or her name, parents, spouse, date of birth, and residence. However, most importantly, the "hukou" system also provides a dual classification of Chinese people (Chan and Zhang 1999). The first classification is the unique permanent residence of an individual, and the second is the rural/urban or agricultural/nonagricultural classification. The first classification hinders workers' migration, and workers working in an area different from their permanent residence could be subject to repatriation. The second classification ties rural families to agricultural work. The "hukou" system limits farmers' options to move to new areas with different jobs; as a result, rural families are forced to work in agriculture for generation after generation.

"Guanxi", which translates to social networks or social connections, plays a role in almost all parts of China (see Gold, Guthrie, and Wank 2002 for a comprehensive introduction), and it is not surprising that guanxi is important in the job search process. According to Bian and Zhang (2001), in the 1990s, 75\% of new entrants into the Chinese labor market and $80 \%$ of current employees who changed jobs relied on guanxi. Bian (2002) argues that, "Indeed, guanxi networks were found to promote job and career opportunities for guanxi users, while constraining those who are poorly positioned in the networks of social relationships." This description from sociologists' perspective clearly echoes economists' idea that "guanxi" leads to the inefficient allocation of talent.

The reform and opening-up policy has relaxed the enforcement of the "hukou" system. In fact, hundreds of millions of Chinese farmers have migrated from inland to coastal areas, where the rapidly growing industry needs new labor. In addition, the quickly growing market economy on China's coast has mitigated the "guanxi" problem. Private firms facing fierce international competition are usually unwilling to accept unqualified workers simply due to "guanxi." All these are underlying reasons for China's improved intergenerational occupational mobility since the 1980s.

For the Indian case, the caste system began as a classification of occupations around 3000 years ago (Deshpande 2000). The system categorizes people into four varnas (ranks or castes), i.e. Brahmins, Kshatriyas, Vaishyas and Shudras, and the untouchable group. Each caste consists of many subcastes, and castes are highly related to occupations. Working in certain occupations is directly correlated with membership to certain castes, and many castes work mainly in one specific occupation (Mayer 2013). The caste system is well known for limiting occupational choices. Therefore, it is not surprising that in the previous section, we find unusually high IOM rates and Altham statistics for India.

Other forms of labor market frictions can lead to the inefficient allocation of talent, such as non-monetary payoffs to different occupations. Chinese society has traditionally placed blue-collar jobs beneath white-collar jobs, and as a result, being a blue-collar worker is a significantly negative signal on the marriage market. The effects of this type of discrimination can be conceptualized as labor market frictions in our model, although they are difficult to measure in the quantitative exercise. Another potential labor market friction is incomplete information. Provided with only partial information, agents on the labor market cannot optimally choose their occupations as in the complete information case. A particular example that fits this paper is that children may grow up with relatively more information about their parents' occupations but have less information about other occupations for which their talents may be a better fit. Ultimately, these children choose their parents' occupations as their own instead of choosing the occupations that best fit their talents. If information in developed countries is more easily available than that in developing countries, a positive correlation between occupational inheritance and GDP per capita results. 


\subsubsection{Human capital accumulation in China and India}

For the purpose of our discussion, we further decompose the process of human capital acquisition into two parts: general academic schooling and occupation-specific training, e.g. vocational education in upper secondary schools and workplace apprenticeship.

The quantity of education received by an average individual in developing countries is usually lower than that in developed countries. We produce Table 2 based on data from Barro and Lee (2013). The average educational attainment for the population aged 25 and older in 2000 is 12.93 years in the US, 6.47 years in China, and 4.41 years in India. The difference in college education, which is especially important in deciding occupations, will be even larger between these countries. The average years of tertiary schooling attained for populations aged 25 and older in 2000 is 1.57 in the US, 0.14 in China, and 0.26 in India. However, it is worth mentioning that the quantity of education received by an average individual in both China and India has been increasing over time. Since 1980, the average years of schooling has increased by 2.6 years for China and by 2.53 years for India.

Table 2: Educational attainment in 2000 (source: Barro and Lee 2013).

\begin{tabular}{lrrr}
\hline & India & China & US \\
\hline Average years of schooling & 4.41 & 6.47 & 12.93 \\
Average years of tertiary education & 0.26 & 0.14 & 1.57 \\
\hline
\end{tabular}

In terms of vocational school education, China has improved dramatically in recent decades, while India lags behind. The OECD (Kuczera and Field 2010) reports that in 2009, approximately 20 million students were enrolled in vocational schools in China - approximately half of the total enrollment in upper secondary education. The Chinese government recently introduced policies to boost upper secondary vocational education, including financial aid to vocational school students. However, it is worth mentioning that China has made these achievements only in the past few years, and the total admissions of upper secondary vocational schools remained lower than 4 million in 2001. Considering that vocational school usually takes $2-3$ years in China, the total number of students in vocational schools was approximately 10 million in 2001 - half of the corresponding number in 2009. However, the quality of vocational schools in China is questionable. Dou (2014) claims, "In the vast majority of vocational education schools in China, kids are not learning anything...we found dropout rates of $50 \%$ in the first 2 years of these programs." Part of the reason for the low quality of vocational schools in China - especially in poor areas - is that the funding of vocational education comes partly from provincial and city governments whose financial abilities vary according to local economic conditions. Moreover, vocational schools in China also suffer from a lack of quality evaluations and a shortage of teachers.

For India, The World Bank (2007) reports that vocational schools enroll less than 3\% of the potential secondary enrollment population, which is far from adequate.

Data on workplace training are limited for both China and India. The Chinese government actively encourages workplace training, but there are few quality standards. Additionally, no formal regulations on workplace training have been well enforced. Similarly, India also has a "weak non-public training market", except in the ICT sector (The World Bank 2007). Workplace training inevitably involves employers' investment in employees and contracts between trainers and trainees. However, a poor judiciary system and binding financial constraints in developing countries will always hamper a socially efficient level of workplace training.

\section{Model}

\subsection{Model setup}

The model is a closed-economy version of Eaton and Kortum (2002) that is embedded with heterogeneous individuals making occupational choices, following Roy (1951). An individual's work efficiency (or quality) is a combination of innate talents and acquired human capital, but there exist different levels of barriers in acquiring human capital and frictions in allocating workers from different family backgrounds. Based on one's own innate talent draw and frictions in the labor market, an individual chooses his or her optimal occupation, consumption, and schooling investment. The collective decisions of all individuals will then determine aggregate productivity.

More specifically, there is a unit measure of individuals grouped by their fathers' occupations (denoted by $i)$, and a total of $M$ different occupations $(J=\{1,2, \ldots, M\})$ in the economy. Each individual is born with innate 
talent $\epsilon=\left(\epsilon_{1}, \epsilon_{2}, \ldots, \epsilon_{j}, \ldots, \epsilon_{M}\right)$ across occupations that is determined by an idiosyncratic draw, where $\epsilon_{j}$ is his particular innate talent for jth occupation. Each individual lives one period, but we further decompose it into two sub-periods to distinguish between the period of accumulating human capital ("childhood") and the period of work ("adulthood"). We denote by s schooling time, and therefore, $(1-s)$ is leisure time, and we denote by $e$ the expenditure on human capital acquisition. In childhood, the acquired human capital $h$ is produced using schooling time input $s$ and resource input $e$ with a Cobb-Douglas production function $h=\delta s^{\phi} e^{\eta}$, where $\delta$ is a parameter measuring the barriers to accumulating human capital. Ultimately, an individual's work efficiency (or overall quality) is $\epsilon h$, a combination of innate talent and acquired human capital. In adulthood, each individual works in an occupation $j \in J$ and earns a labor income subject to labor market frictions $\tau$, that is, $(1-\tau) \cdot w \epsilon h$, where $w$ is the wage for one unit of effective labor. Then, the individual repays education input $e$ and consumes the rest $c$.

In this model, innate talent $\epsilon$ is public information and determines an individual's state jointly with family group $i$. Individuals face different levels of barriers to acquiring human capital and labor market frictions depending on the family group and working occupation. In other words, $\delta$ and $\tau$ come with subscripts $i$ and $j$, where $\delta_{i j}$ and $\tau_{i j}$ are the corresponding terms for an individual from group $i$ and working in occupation $j$. We will infer these barriers and frictions from the data - the key component of the quantitative exercise of this paper. When $i=j$, we expect a high value of $\delta$ and a low value of $\tau$, as working in the same occupation as one's father could potentially occur as a result of the transfer of knowledge within the family, social networks, etc.

In the model, an individual makes an occupational choice decision and decides on schooling timing and resource input and consumption based on this state. The optimization process could be decomposed into twostep backward induction. In the first step, given a particular occupation, an individual chooses the optimal schooling timing and resource input and consumption and calculates the indirect utility for this occupation; in the second step, an individual compares the indirect utility of different occupations and chooses the best occupation.

According to the model setup, the individual maximization problem can be written as

$$
\begin{gathered}
\max _{j \in J, c_{i j}, s_{j j}, e_{i j}} U_{(\epsilon, i)}(j)=\log \left(1-s_{i j}\right)+\beta \log \left(c_{i j}\right) \\
\text { s.t. } c_{i j}=\left(1-\tau_{i j}\right) \cdot w_{j} \epsilon_{j} h_{i j}-e_{i j} \\
h_{i j}=\delta_{i j} s_{i j}^{\phi_{j}} e_{i j}^{\eta}
\end{gathered}
$$

Innate talents are drawn from a Frechet distribution as in Eaton and Kortum (2002):

$$
\Lambda_{i}(\epsilon)=\exp \left\{-\left[\sum_{j=1}^{N}\left(T_{i j} \epsilon_{j}^{-\theta}\right)\right]\right\}
$$

The parameter $T_{i j}$ governs the location of the distribution: a larger $T_{i j}$ implies a greater likelihood of high talent in occupation $j$ for group $i$; the parameter $\theta$ is the shape parameter and governs the dispersion of the distribution.

The total amount of effective labor supply in occupation $j$ can thus be written as

$$
H_{j}=\sum_{i=1}^{M} \pi_{i}^{L} p_{i j} \cdot E_{i}\left[h_{i j} \epsilon_{i j} \mid j\right]
$$

As defined in Section $2, \pi^{L}$ is the distribution of fathers' occupations, that is, the distribution of groups, and $p_{i j}$ is the probability of choosing occupation $j$ conditional on group $i$. Therefore, $\pi_{i}^{L} p_{i j}$ is the total measure of people who are from group $i$ and work in occupation $j . E_{i}\left[h_{i j} \epsilon_{i j} \mid j\right]$ is the conditional mean of worker quality for all individuals from group $i$ working in occupation $j$. As a result, $\pi_{i}^{L} p_{i j} \cdot E_{i}\left[h_{i j} \epsilon_{i j} \mid j\right]$ is the total amount of effective labor that individuals from group $i$ provide to occupation $j$, and the total amount of effective labor supply in occupation $j$ is a simple summation over all groups.

There is a representative firm that hires all occupations of workers and produces final goods according to the CES production function: 


$$
\begin{gathered}
\max _{j, c, s} Y-\sum_{j=1}^{M} w_{j} H_{j} \\
\text { s.t. } Y=\left\{\sum_{j=1}^{M}\left(A_{j} H_{j}\right)^{\frac{\sigma-1}{\sigma}}\right\}^{\frac{\sigma}{\sigma-1}}
\end{gathered}
$$

where $A_{j}$ is occupation-specific productivity. According to this production function, the marginal output of an individual depends not only on his own quality but also on the occupation productivity. In equilibrium, this $A_{j}$ would determine the occupation-specific wage $w_{j}$ for each unit of effective labor.

\section{Definition of competitive equilibrium:}

Given productivity $A$, human capital accumulation coefficient $h$, and labor market friction $\tau$, the competitive equilibrium is a set $\{c, s, e, w, H\}$ such that

(1) Given an innate talent draw $\epsilon$, group $i$, and market wages $w$, each individual's occupational choice $j$, consumption $c$, and schooling inputs $s$ and $e$ solve the individual maximization problem.

(2) Given productivity $A$ and market wages $w, H$ solves the representative firm's maximization problem.

(3) The labor market clears for each occupation.

(4) The goods market clears.

\subsection{Model solution}

Due to the properties of the Frechet distribution, this model has a solution that is dependent solely on wages. We present key equations in this subsection, and further details can be found in Appendix A.

An important statistic that links individual choice and macroeconomic variables is every group's probability of choosing each occupation. To solve for this, we first solve the individual maximization problem using twostep backward inductions. First, for an individual with endowment $\epsilon$ from group $i$, calculate his indirect utility in occupation $j$, that is, $U_{i j}(\epsilon)$ as in Equation (22) in Appendix A. Second, compare across $j \in J$ to search for the best occupation. Then, we can integrate individual choices over the distribution of innate talent and solve for $p_{i j}$ :

$$
\begin{gathered}
p_{i j}=\frac{\psi_{i j}^{\theta}}{\sum_{k} \psi_{i k}^{\theta}} \\
\psi_{i j}=\delta_{i j}\left(1-\tau_{i j}\right) T_{i j}^{1 / \theta} w_{j} s_{j}^{\phi_{j}}\left(1-s_{j}\right)^{\frac{1-\eta}{\beta}}
\end{gathered}
$$

We can also solve for another important statistic - the average quality of workers from group $i$ working in occupation $j$ - by taking advantage of the Frechet distribution:

$$
E_{i}\left[h_{i j} \epsilon_{i j} \mid j\right]=\frac{1}{w_{j}\left(1-\tau_{i j}\right)} \eta^{\frac{1}{1-\eta}}\left(1-s_{j}\right)^{-\frac{1}{\beta}}\left(\sum_{k} \psi_{i k}^{\theta}\right)^{\frac{1}{\theta}} \cdot \Gamma\left(1-\frac{1}{\theta(1-\eta)}\right)
$$

From Equation (14), we can solve for the average income of workers from group $i$ working in occupation $j$ :

$$
\begin{aligned}
I N C_{i j} & =\left(1-\tau_{i j}\right) w_{j} E_{i}\left[h_{i j} \epsilon_{j} \mid j\right] \\
& =\eta^{\frac{1}{1-\eta}}\left(1-s_{j}\right)^{-\frac{1}{\beta}}\left(\sum_{k} \psi_{i k}^{\theta}\right)^{\frac{1}{\theta}} \cdot \Gamma\left(1-\frac{1}{\theta(1-\eta)}\right)
\end{aligned}
$$

Holding group $i$ constant, we determine Equation (16) by comparing children's average income of different groups for any occupation: 


$$
\frac{I N C_{g j}}{I N C_{h j}}=\frac{\left(\sum_{k} \psi_{g k}^{\theta}\right)^{\frac{1}{\theta(1-\eta)}}}{\left(\sum_{k} \psi_{h k}^{\theta}\right)^{\frac{1}{\theta(1-\eta)}}}
$$

We further define an overall measure of barriers and frictions $\kappa$ with the following equation:

$$
\kappa_{i j}=\left[\delta_{i j}\left(1-\tau_{i j}\right)\right]^{-1}
$$

By definition, $x$ should capture the strength of the elements that impede growth. As $x$ increases, these elements' strength increases, and the economy suffers a larger productivity loss. From the occupational choice perspective, the variable affects each individual's occupational choices and determines the aggregate intergenerational occupation transition pattern on the macro level. Estimating $\kappa$ is a crucial step in our quantitative exercise, and thanks to the model's design, we can directly infer $x$ from the data. Combining Equations (12), (16) and (17), we reach a key equation:

$$
\frac{\kappa_{h j}}{\kappa_{i j}}=\frac{\delta_{i j}\left(1-\tau_{i j}\right)}{\delta_{h j}\left(1-\tau_{h j}\right)}=\left(\frac{T_{h j}}{T_{i j}}\right)^{\frac{1}{\theta}} \cdot\left(\frac{I N C_{h j}}{I N C_{i j}}\right)^{-(1-\eta)} \cdot\left(\frac{p_{h j}}{p_{i j}}\right)^{-\frac{1}{\theta}}
$$

The average income for groups and occupations and an intergenerational occupational transition matrix can be directly estimated from the data. That is, we can instantly compute the last two terms on the right-hand side of Equation (18). Then, the right-hand side degenerates to the parameter $T$, which governs how innate talent can be transferred between generations. Additionally, from Equation (18), we can estimate $x$, but we cannot further distinguish between $\delta_{i j}$ and $\left(1-\tau_{i j}\right)$. Therefore, our quantitative exercises will continue by assuming two polar cases, that is, the case that $\tau_{i j}=0$ and the case that $\delta_{i j}=1$.

\section{Data and calibration}

\subsection{Data}

Similar to the empirical analysis in Section 2, we rely on the ISSP 2009 and IPUMS International as data sources. However, we use mainly census data from IPUMS International in this section because we need to estimate the occupation transition matrix in the quantitative exercises. If there are $M$ occupations in the economy and, consequently, $M^{2}$ elements in the transition matrix, we therefore, on average, have only $1 / M^{2}$ of the total number of observations to estimate each cell. This problem could be even more serious because the occupation distribution is not even; therefore, a large sample size is required, and thus, census data are a better choice.

More specifically, we use China's 1982 and 1990 censuses, the Indian Employment Survey for 1993, 1999, and 2004, and US census data from 1990, 2000, 2005, and 2010. The US census data include 5\% percent of the population for 1990 and 2000 and 1\% of that for 2005 and 2010. That is, we have 12,501,046 observations for $1990,14,081,466$ observations for 2000, 2,878,380 observations for 2005, and 3,061,692 observations for 2010. We still consult IPUMS 2009 data for two reasons: (1) neither of China's censuses includes income information, but these data are available in the ISSP 2009; and (2) China's 2010 census data are not available to the public, and we must therefore use the ISSP 2009 as a substitute to calculate the productivity gain for China from the 1980s to date.

For all data, we use the ISCO88 1-digit occupation classification. There are 10 occupations at this level, but we drop "Armed Forces" because it is difficult to measure its output, and in many countries, being a soldier is only a temporary occupation. The detailed 1-digit ISCO88 is listed in Table 11 of Appendix C.

We use four sets of data to parameterize the whole model: (1) intergenerational occupational transition matrix $P=\left\{p_{i j}\right\}$; (2) average occupation income $\left\{I N C_{i}\right\}$; (3) average income ratios across all groups; and (4) average schooling in one particular group (i.e. farmers). These four sets of data include $M(M-1), M, M-1$, and 1 moments, respectively. In total, we use $M(M+1)$ moments for the estimation process.

Table 3: China: intergenerational occupational transition matrix. 


\begin{tabular}{lrrrrrrrrr} 
Father's Occupation & $\mathbf{1}$ & $\mathbf{2}$ & $\mathbf{3}$ & $\mathbf{4}$ & $\mathbf{5}$ & $\mathbf{6}$ & $\mathbf{7}$ & $\mathbf{8}$ & $\mathbf{9}$ \\
\hline 1 & 0.0074 & 0.0493 & 0.1265 & 0.0740 & 0.0985 & 0.2345 & 0.2658 & 0.0868 & 0.0571 \\
2 & 0.0057 & 0.1062 & 0.1275 & 0.0573 & 0.0777 & 0.2245 & 0.2738 & 0.0734 & 0.0538 \\
3 & 0.0047 & 0.0266 & 0.0886 & 0.0352 & 0.0695 & 0.4206 & 0.2466 & 0.0652 & 0.0431 \\
4 & 0.0075 & 0.0376 & 0.1101 & 0.0905 & 0.1198 & 0.1259 & 0.3337 & 0.1035 & 0.0713 \\
5 & 0.0058 & 0.0110 & 0.0400 & 0.0184 & 0.1871 & 0.3944 & 0.2412 & 0.0583 & 0.0438 \\
6 & 0.0012 & 0.0019 & 0.0086 & 0.0014 & 0.0053 & 0.9074 & 0.0599 & 0.0091 & 0.0052 \\
7 & 0.0022 & 0.0097 & 0.0345 & 0.0146 & 0.0553 & 0.3480 & 0.4086 & 0.0687 & 0.0584 \\
8 & 0.0019 & 0.0131 & 0.0427 & 0.0183 & 0.0733 & 0.2973 & 0.3139 & 0.1619 & 0.0777 \\
9 & 0.0092 & 0.0177 & 0.0512 & 0.0246 & 0.0847 & 0.2213 & 0.3771 & 0.1007 & 0.1133 \\
\hline
\end{tabular}

Table 4: India: intergenerational occupational transition matrix.

\begin{tabular}{|c|c|c|c|c|c|c|c|c|c|}
\hline \multirow[b]{2}{*}{ Father's Occupation } & \multicolumn{9}{|c|}{ Son's Occupation } \\
\hline & 1 & 2 & 3 & 4 & 5 & 6 & 7 & 8 & 9 \\
\hline 1 & 0.5959 & 0.0444 & 0.0152 & 0.0248 & 0.0687 & 0.0815 & 0.0861 & 0.0283 & 0.0550 \\
\hline 2 & 0.1432 & 0.2654 & 0.0409 & 0.0588 & 0.0479 & 0.2996 & 0.0751 & 0.0335 & 0.0358 \\
\hline 3 & 0.1232 & 0.0905 & 0.2685 & 0.0606 & 0.0934 & 0.1424 & 0.1184 & 0.0481 & 0.0549 \\
\hline 4 & 0.1368 & 0.1251 & 0.0463 & 0.1570 & 0.0717 & 0.2410 & 0.1283 & 0.0430 & 0.0508 \\
\hline 5 & 0.0605 & 0.0413 & 0.0159 & 0.0337 & 0.3976 & 0.1389 & 0.1456 & 0.0589 & 0.1075 \\
\hline 6 & 0.0417 & 0.0272 & 0.0077 & 0.0102 & 0.0154 & 0.7381 & 0.0564 & 0.0228 & 0.0806 \\
\hline 7 & 0.0335 & 0.0246 & 0.0109 & 0.0185 & 0.0481 & 0.0998 & 0.6135 & 0.0489 & 0.1023 \\
\hline 8 & 0.0531 & 0.0347 & 0.0163 & 0.0375 & 0.0881 & 0.1108 & 0.1996 & 0.3143 & 0.1455 \\
\hline 9 & 0.0221 & 0.0085 & 0.0041 & 0.0075 & 0.0385 & 0.1195 & 0.1045 & 0.0329 & 0.6623 \\
\hline
\end{tabular}

We pool data from the 1982 and 1990 Chinese censuses to generate Table 3, and we pool the 1993, 1999, and 2004 Indian Employment Survey data to generate Table 4. We pool these data to eliminate short-term fluctuations and because there is no significant difference between datasets. We also report the intergenerational occupational transition matrix for the US in Table 12 in Appendix C.

A quick glimpse of the table illuminates several observations: 1) In comparing the diagonal elements between China and India, which indicate the degree of occupational inheritance, China's occupational inheritance occurs mainly among farmers (cell $(6,6))$ and craft and related trade workers (cell $(7,7)$ ), while India has universally high occupational inheritance among all occupations; and 2) in both China and India, farming is the occupation with the highest inheritance rate, while for the US case, the occupational inheritance rate is around the median across all occupations.

In addition, we calculate the average income for each occupation in China and India. For China, data are reported as the annual occupational income in CNY; for India, it is reported as the weekly wage and salary income in INR; for the US, it is reported as the yearly wage and salary income in USD. When we feed these data into the model, they would be normalized internally so that direct comparisons are justified. Similarly, we also calculate relative average incomes across groups for each country.

\subsection{Estimation and calibration of the parameters}

Parameters $\{\theta, \eta\}$ govern the distribution of talent; however, the distribution of human talent is not directly observable. Fortunately, we can still infer this distribution from income information. According to the model, the distribution of income within an occupation for a particular group is Frechet, and the shape parameter is $\theta(1-\eta)$, which decides the moments of the distribution. Similar to HHJK (2016), we first regress income on occupation-group dummies using census data. The variance in the residuals would be exactly equal to the variance of a Frechet distribution with a shape parameter $\theta(1-\eta)$. Therefore, we can pin down that $\theta(1-$ $\eta$ ) is 4.32 for China, 2.44 for India, and 3.13 for the US. The parameter $\eta$ is the resource input share in the production of acquired human capital and is equal to the ratio of human capital accumulation spending and output. Following Hsieh et al. (2016), we use the ratio of the share of education spending of output to the labor share of output as a proxy for $\eta$. We determine the share of education spending in GDP for China from the China's Bureau of Statistics website $^{8}$ and that for India from the OECD's World Education Indicators $2005 .^{9}$ In addition, we determine the average labor shares of China and India from the Karabarbounis and Neiman (2013) data. Ultimately, we find that $\eta$ is 0.111 for China and 0.156 for India. We obtain the value 0.103 for the US directly from HHJK (2016). 
In the model, $\beta$ determines the Mincerian return, i.e. how one's length of education is reflected in his or her income. A survey of the Mincerian return in China suggests a wide range of estimation results, starting from $3.29 \%{ }^{10}$ in Johnson and Chow (1997), 10.24\% in Zhang (2011), and 17.26\% in Awaworyi and Mishra (2014), and the situation is very similar for India. To simplify, we choose the level $\beta=0.693$ to match the Mincerian return in the US of $12.7 \%$ as shown in HHJK (2016) as the benchmark. ${ }^{11}$ In addition, we choose the elasticity of substitution between different sectors $\sigma=3$, following the literature. We calculate the average years of schooling among farmers in China and India using census data, which are 4.8 years and 5.2 years, respectively. This step helps us calibrate the schooling of a benchmark occupation $s_{0}$, and we then further calibrate $\phi$ using Equations (19) and (29) in Appendix A. Finally, we determine occupation-specific $A_{j}$ to clear labor markets for all occupations.

Parameter $T$ determines how innate talent, the human capital determined by "nature" when one is born, is transferred between generations. It is not impossible that men in certain occupations would father children born with superior abilities for certain occupations. For example, the children of athletes are likely to be physically stronger or faster than average children. Unfortunately, it is impossible to directly evaluate these differences. In addition, if this mechanism is truly significant in magnitude, we should observe very serious occupational inheritance in well-developed market economies such as the US, while in fact, we observe very limited inheritance from the data. Therefore, we begin with the assumption that "all men are created equal". That is, we assume that the distribution of talent is constant across all groups, and $T_{i j}=1$. We will relax this assumption in an extension in Section 5.4 to check the extent to which this assumption affects the results.

Finally, we aim to infer the aggregate measure of the previously discussed impediments, matrix $\left\{\kappa_{i j}\right\}_{M \times M}$, for China, India, and the US. We consider these $\left\{\kappa_{i j}\right\}_{M \times M}$ as the deep parameters that distinguish developed countries from developing countries. We normalize $\kappa_{i i}=1$ for all $i$, i.e. when sons inherit their fathers' occupations, the impediments they face are normalized to 1 . Then, the estimation of $\left\{\kappa_{i j}\right\}_{M \times M}$ simply follows Equation (18), which uses elements in the intergenerational occupational transition matrix and income information as inputs.

\section{Quantitative exercises}

We execute mainly two sets of counterfactual experiments. First, in the benchmark experiment, we aim to measure the labor productivity gains in China and India if these impediments were reduced to the US level. Second, we aim to calculate the productivity gain from this perspective after the reform and opening-up policy was executed by comparing China's situation in the 1980s with that in 2009. The first experiment can provide growth potential for developing countries, and the second measures the degree of realization of this growth potential for China during that period.

In the implementation, we keep China and India's calibrated values for $\left\{A, T, s_{0}\right\}$ fixed and replace aggregate measures of impediments, i.e. $\kappa_{C N}$ and $\kappa_{I N}$, with the US value $\kappa_{U S}$ for the first experiment and with China's 2009 value $\kappa_{C N 2009}$ for the second experiment. Then, we solve for the new equilibrium and compare it with real data.

In Section 5.1, we conduct the first experiment; in Section 5.2, we conduct the second one. In Section 5.3, we calculate the accompanying change in intergenerational income correlations for these two experiments. So far, we have assumed that $T_{i j}=1$ for our quantitative exercises throughout the paper, i.e. we assume that sons' innate talents are ex ante similar across groups and occupations. We relax this assumption in Section 5.4 to determine the extent to which our results depend on this assumption.

\subsection{Benchmark experiments}

The results of the counterfactual experiments are listed in Table 5. These results indicate that both China and India can experience gains by a large magnitude by reducing the impediments to IOM. Comparing these two countries, we find that the gain for India is especially large. According to our previous empirical results, we can attribute this gain to the fact that it is very unlikely for Indian workers to move to a new occupation, regardless of their fathers' occupations. The caste system is likely the most important reason for this result.

Table 5: Benchmark: productivity gains.

\begin{tabular}{lrr} 
& $\boldsymbol{\tau}_{i j}=\mathbf{0}$ & $\boldsymbol{\delta}_{i j}=\mathbf{1}$ \\
\hline China & $74.80 \%$ & $60.26 \%$ \\
India & $178.33 \%$ & $107.42 \%$ \\
\hline
\end{tabular}




\subsection{Accounting for China: the $1980 s-2009$}

As discussed in previous sections, China has made significant improvements in several dimensions in recent decades. First, China's reform and opening-up policy has relaxed constraints such as "hukou" (household registration), which tied farmers to field work and restricted internal migration, and as a result, many young farmers have moved to coastal cities to work in new occupations. Second, the rapid expansion of the market economy on the coast has gradually mitigated the "guanxi" problem. Compared with state-owned enterprises, private firms facing intense international competition are less willing to hire simply because of "guanxi". Due to the expansion of the market economy, the relative proportion of state-owned enterprises has decreased dramatically since the 1980s. Third, China has improved its general academic and vocational school education, as discussed in Section 2.3.3.

Table 6: China in 2009: intergeneration occupational transition matrix.

\begin{tabular}{lrrrrrrrrrrr}
\hline & \multicolumn{4}{c}{ Son's Occupation } \\
\cline { 2 - 11 } Father's Occupation & $\mathbf{1}$ & $\mathbf{2}$ & $\mathbf{3}$ & $\mathbf{4}$ & $\mathbf{5}$ & $\mathbf{6}$ & $\mathbf{7}$ & $\mathbf{8}$ & $\mathbf{9}$ \\
\hline 1 & 0.1250 & 0.2083 & 0.0952 & 0.0476 & 0.2083 & 0.0774 & 0.0893 & 0.0595 & 0.0893 \\
2 & 0.0424 & 0.1780 & 0.0847 & 0.0254 & 0.1864 & 0.1441 & 0.0932 & 0.1186 & 0.1271 \\
3 & 0.1077 & 0.2154 & 0.1385 & 0.1077 & 0.1231 & 0.0615 & 0.0615 & 0.1077 & 0.0769 \\
4 & 0.0010 & 0.2495 & 0.0832 & 0.0010 & 0.0832 & 0.1663 & 0.1663 & 0.0832 & 0.1663 \\
5 & 0.0570 & 0.1329 & 0.1013 & 0.0127 & 0.2785 & 0.1076 & 0.0949 & 0.0886 & 0.1266 \\
6 & 0.0387 & 0.0490 & 0.0329 & 0.0161 & 0.1075 & 0.5300 & 0.0716 & 0.0497 & 0.1045 \\
7 & 0.0895 & 0.0789 & 0.0842 & 0.0368 & 0.1842 & 0.0842 & 0.2000 & 0.1263 & 0.1158 \\
8 & 0.0522 & 0.1478 & 0.0696 & 0.1043 & 0.1391 & 0.0783 & 0.1304 & 0.1130 & 0.1652 \\
9 & 0.0531 & 0.0885 & 0.1062 & 0.0177 & 0.2655 & 0.0619 & 0.0885 & 0.1062 & 0.2124 \\
\hline
\end{tabular}

In order to examine the extent to which China has gained through reductions in occupational inheritance, we again use data from the ISSP 2009 and calculate the intergenerational occupational transition matrix as in Table 6. It can be directly observed from this table that the diagonal elements are very moderate, that is, the occupational inheritance rate is not high for any occupation.

Table 7: China: productivity gains from the 1980s to 2009.

\begin{tabular}{|c|c|c|}
\hline & $\tau_{i j}=0$ & $\delta_{i j}=1$ \\
\hline Benchmark & $74.80 \%$ & $60.26 \%$ \\
\hline 2009 & $55.51 \%$ & $53.73 \%$ \\
\hline 2009/Benchmark & $74.21 \%$ & $89.16 \%$ \\
\hline
\end{tabular}

The counterfactual experiment results are listed in the second row of Table 7. We also list the results from the benchmark counterfactual from Section 5.1 in the first row for comparison. In the third row, we list the realized growth potential for China from the 1980s to 2009. Our results suggest that China has realized $74-89 \%$ of the growth potential from the US counterfactual experiment in recent decades. These results indicate that China has made great progress towards reducing occupational inheritance; however, the country also needs to find other ways to continue its sustainable growth in the future.

\subsection{Implications for intergenerational income correlation}

In addition to affecting occupational choices and hurting productivity, barriers to human capital accumulation and labor market frictions can impact intergenerational income elasticity. If children from low-income families are constrained from moving away from low-income occupations, the economy would display very high intergenerational income elasticity. Our model incorporates occupational-level income information for both generations, and therefore, it allows us to analyze the relationship between the incomes of both generations. More specifically, for fathers, we have the distribution of occupations $\left(\pi^{L}=\left(\pi_{1}^{L}, \pi_{2}^{L}, \ldots, \pi_{M}^{L}\right)\right)$ and the average income for each occupation $\left(w^{1}=\left(w_{1}^{1}, w_{2}^{1}, \ldots, w_{M}^{1}\right)\right)$, where superscripts denote the first generation. We can also calculate for both the real data and the counterfactual experiment equilibrium the intergenerational occupational transition matrix $P$ and the average income for each group $\left(w^{2}=\left(w_{1}^{2}, w_{2}^{2}, \ldots, w_{M}^{2}\right)\right)$. Based on the 
above information, we can calculate the correlation between the two generations' incomes with the following equation:

$$
\rho\left(w^{1}, w^{2}\right)=\sum_{i=1}^{M} \sum_{j=1}^{M} \pi_{i}^{L} p_{i j}\left(w_{i}^{1}-E\left[w^{1}\right]\right)\left(w_{j}^{2}-E\left[w^{2}\right]\right)
$$

We should note that this intergenerational income correlation measure does not include intra-occupation income variation, which would generate a higher value. This issue does not trouble us because we do not intend to analyze this value itself; instead, we aim to focus on the change in this measure after implementing the counterfactual experiment. For example, for the benchmark experiment, our research question is essentially this; we know from Section 5.1 that if impediments to occupational change were reduced to the US level, China and India could increase their labor productivity - but how would this affect the intergenerational income correlation?

Table 8: Change in intergenerational income correlation in counterfactuals.

\begin{tabular}{lllrr}
\hline & & & Experiment 1 & \multicolumn{2}{c}{ Experiment 2 } \\
\cline { 3 - 5 } & & China & India & -0.43 \\
\hline \multirow{2}{*}{$\Delta \rho$} & $\tau_{i j}=0$ & -0.54 & -0.42 & -0.13 \\
& $\delta_{i j}=1$ & -0.53 & -0.10 \\
\hline
\end{tabular}

According to Table 8, removing barriers and frictions are helpful in reducing intergenerational income correlations. Both China and India experience very large magnitudes of reduction, approximately 0.53 0.54 for China and 0.42 0.43 for India. The difference between China and India is minor and is likely to to the more uneven distribution of labor market frictions across occupations in China than in India. In the second experiment, China also experiences a reduction in intergenerational income correlations, but the magnitude of the change is not as significant as in the first experiment. This result indicates that the removal of barriers to human capital accumulation and labor market frictions between the 1980s and 2009 is uneven across occupations for China, and its effect on relaxing productivity constraints is greater than that on promoting income equality across society.

Regardless of the differences in magnitudes, we aim to emphasize the general conclusions that removing elements impeding intergenerational occupational change not only helps in improving productivity but also reduces inequality. This option promotes efficiency and social justice simultaneously, which should be considered by policymakers when dealing with "hukou" policy in China and the caste system in India.

\subsection{Experiment: relaxing equal innate talent assumption}

So far, we have assumed that the parameters of innate talent distribution are constant regardless of group and occupation, i.e. $T_{i j}=1$. However, it may be true that men working in certain occupations may father children with greater innate talent to work in the same occupation. In this case, we would expect $T_{i j}$ to vary across $i$ and $j$. However, we are unlikely to completely estimate or correct the exact value of $T_{i j}$. Instead of attempting to find correct values for $T_{i j}$, we simply assign values to $T_{i j}$ with reasonable alternative assumptions and check the extent to which our results are sensitive to this assumption.

Since the occupation for which children are born with superior ability is most likely to be the family occupation, we will change only the values of $T_{i i}$ but maintain the assumption that $T_{i j}=1, \forall i \neq j$. In addition to conducting the benchmark counterfactual experiment, we impose three different sets of $T_{i j}$ and reproduce the results in order to determine how our results rely on this assumption. The three sets of values that we choose for this experiment are (1) $T_{i i}=1.5^{\theta}$; (2) $T_{i i}=2^{\theta}$; and (3) $T_{i i}=$ (skill level) $^{\theta}$. The skill level in case (3) is introduced by International Labour Office (1990) to measure the degree of complexity and skill requirement for occupations in ISCO88. There are four skill levels, which range from 1 to 4 , and details can be found in Table 11.

Table 9: Relaxing the equal innate talent assumption. 


\begin{tabular}{lrrrr} 
& $\boldsymbol{\tau}_{i j}=\mathbf{0}$ & $\boldsymbol{\delta}_{i j}=\mathbf{1}$ & $\boldsymbol{\tau}_{i j}=\mathbf{0}$ & $\boldsymbol{\delta}_{i j}=\mathbf{1}$ \\
\hline Benchmark & $74.80 \%$ & $60.26 \%$ & $178.33 \%$ & $107.42 \%$ \\
$T_{i i}=1.5^{\theta}$ & $79.18 \%$ & $57.02 \%$ & $157.94 \%$ & $101.50 \%$ \\
$T_{i i}=2^{\theta}$ & $85.62 \%$ & $70.99 \%$ & $136.73 \%$ & $102.77 \%$ \\
$T_{i i}=$ skill level) $^{\theta}$ & $78.08 \%$ & $52.96 \%$ & $190.13 \%$ & $105.11 \%$ \\
\hline
\end{tabular}

How large are our values of $T_{i i}$ in these experiments? Here, we aim to provide some straightforward intuition. Assume that innate talent follows a Frechet distribution, as in Equation (8). According to the property of the Frechet distribution, it follows that $E_{i}\left(\epsilon_{j}\right) \propto T_{i j}^{\frac{1}{\theta}}$. In other words, when we impose $T_{i i}=2^{\theta}$, a worker working in the same occupation as his father would, on average, be twice as efficient as one working in a different occupation. Therefore, we consider that the three sets of values are large enough to detect problems in our results if the equal innate talent assumption is violated. The results for this experiment are listed in Table 9. According to this table, relaxing the equal innate talent assumption may shift the results slightly; however, this shift does not fundamentally change our conclusion.

\subsection{Extension: allowing for an additional distortion creating the public sector earnings premium}

In this section, we want to link the misallocations implied by the intergenerational occupational choices with the public-private wage premium in Cavalcanti and Santos (2015). In order to make such link, the first issue to solve is that we classify jobs by occupations in this paper while it is done by sectors in Cavalcanti and Santos (2015). Fortunately, China provides a particular case to overcome this problem. In the early 1980s, China was mostly a socialistic country with most enterprises being state-owned. In fact, most workers in the country were on the government's payroll in the broad sense except farmers and the self-employed. It was impossible for the government to provide an income premium for all its employees especially for the unskilled workers considering their large number. Therefore, if the public sector earnings premium existed, it was intended for occupations with relatively high social status rather than all employees of the government. We pick three occupations ("Legislators, senior officials and managers", "Professionals", and "Clerks" ) as best candidates for wage premiums, and we would treat them as "the public sector" in this Section. The choice of occupations designated as the public sector would not change our conceptual analysis on the interactions of different distortions, but it is possible to make some quantitative differences. (6):

We revise our model setup to allow for the public-private wage premium by revising the income Equation

$$
c_{i j}=\left(1+t_{i j}\right) \cdot\left(1-\tau_{i j}\right) \cdot w_{j} \epsilon_{j} h_{i j}-e_{i j}
$$

where the term $\left(1+t_{i j}\right)$ stands for the distortion of the public sector earnings, and it could be further simplified to $t_{j}$ if we maintain the assumption that the public sector wage premium is independent of an individual's group. To effectively represent a public sector wage premium, $t_{i j}$ should be greater than 0 when $j$ is the public sector and 0 otherwise. Adding such a new term would change all the equilibrium conditions of the model, but only up to the level that we now replace $\left(1-\tau_{i j}\right)$ by $\left(1+t_{i j}\right) \cdot\left(1-\tau_{i j}\right)$. For example, the Equation (13) is now:

$$
\psi_{i j}=\delta_{i j}\left(1+t_{i j}\right) \cdot\left(1-\tau_{i j}\right) T_{i j}^{1 / \theta} w_{j} s_{j}^{\phi_{j}}\left(1-s_{j}\right)^{\frac{1-\eta}{\beta}}
$$

Since the occupation choice pattern is still determined by $\psi_{i j}$ as in Equation (12), the new distortion also affects the allocation of talents into different occupations according to Equation (20).

When we reduce the barriers of occupational choices by reducing $\tau_{i j},\left(1+t_{i j}\right)$ would magnify the amount of barrier being removed. This is how the existence of this new distortion increases productivity gains when removing barriers of intergenerational occupational choices. However, if $\left(1+t_{i j}\right) \cdot\left(1-\tau_{i j}\right)$ is greater than 1 in the counterfactual, the public sector becomes too attractive and would induce inefficiently too many workers into the sector through the interactions with intergenerational occupational choices, which could potential hurt the labor productivity. Therefore, the overall effects of the interactions of the two misallocation sources really depend on their quantitative details.

We do not have data on the $t_{i j}$. Instead of arbitrarily choosing the values of $t_{i j}$, we use a "detour" method: we construct a new equilibrium with designated levels of the public sector earnings premium and running counterfactual experiments based on this new equilibrium. More specifically, we implement quantitative exercises following the following procedures: 
Step 1: Calibrate the model just as in the benchmark case in the Sections 5.1.

Step 2: Add the new public sector wage distortion as in Equation (19), and calculate the new equilibrium with this new public sector. This new equilibrium would be the starting point for further counterfactual experiments. By construction, the public sector wage premium is completely a result of the corresponding underlying distortion.

Step 3: Keep the new public sector wage distortion but remove the occupational choice barriers in the counterfactual. This is again similar to the benchmark case in the Sections 5.1.

Step 4: Compare the equilibrium outcomes in the Step 2 and Step 3, and calculate the productivity gain of removing occupational choice barriers under the existence of the new public sector wage premium distortion.

This "detour" method relieves us from taking stand in the level of the public sector wage premium. In addition, since we are able to choose the designated level of the new public sector wage premium distortion, we are able to further explore how the size of the new distortion could affect the gains of productivity when removing the occupational choice barriers.

We list the results in the Table 10. Because we want to study different sources of misallocation, here we only focus on the case that $\delta_{i j}=1$ because in the other case that $\tau_{i j}=0$, the occupational choice distortions would be shut down. Column (1) is the productivity gain of the benchmark case in the Sections 5.1. It is effectively the case with zero public sector wage premium and we list it here for comparison. Column (2) is the productivity gain when the public sector wage distortion is set to be $25 \%$ uniformly for all workers just as in Cavalcanti and Santos (2015). In Column (3), we allow $t_{i j}$ to vary by group. It is the productivity gain when the new public sector wage distortion is set to be $40 \%$ for workers whose fathers are farmers and $25 \%$ for all the rest groups. Since workers from the farmer family are usually the unfavorably treated group in China, this could be considered as a government policy to help this socially vulnerable group.

Table 10: Productivity gains with different levels of public sector wage premiums.

\begin{tabular}{llll}
\hline Public sector wage & (1) Zero & (2) Uniform 25\% & (3) Group dependent \\
premium & $60.26 \%$ & $60.65 \%$ & $61.16 \%$ \\
\hline Productivity gain & 6 & \\
\hline
\end{tabular}

Comparing Columns (1) and (2), the results suggest that with presence of the public sector earnings premium, the gains of productivity by reducing occupational inheritance become slightly larger. This is especially true if the government gives additional favor to workers grown up in the farmer family as suggested in Column (3). In other words, in China's case, the public sector earnings premium aggravates the effects of the barriers to intergenerational occupational choices on the labor productivity, even though the magnitude is not large.

\section{Conclusions}

A large body of literature has aimed to explain the productivity gap between developed countries and developing countries. Traditionally, researchers have targeted barriers to acquiring human capital as one of the possible explanations for the divergence in developing countries. However, past studies on this topic focus only on the mechanisms behind low educational attainment in developing countries, e.g. financial constraints, while ignoring that a large portion of human capital is heterogeneous across occupations and that there are many other determinants of occupational choice during the transition from school to the workplace. By using a new occupational choice framework, this paper provides a more comprehensive explanation. We estimate deep parameters, i.e. coefficients of labor market frictions and coefficients of barriers to accumulating human capital, and investigate the aggregate implications of the particular sociological phenomenon of occupational inheritance.

This paper first contributes to the empirical literature on intergenerational occupational mobility. We document the significant correlation between IOM rates and GDP per capita. We also contribute to the literature by systematically calculating the Altham statistics for intergenerational occupational transition matrices across countries, distinguishing the interaction effect from the prevalence effect. In our quantitative exercises, we calculate the extent to which China and India could improve their labor productivity by reducing the aforementioned impediments to reaching the levels observed in the US. Our counterfactuals suggest that the productivity gain is large for China and even larger for India. The findings in this paper suggest that removing impediments to occupational choice would lead to significant productivity gains for developing countries. In addition, we find that this productivity gain is accompanied by a reduction in correlations between intergenerational incomes; thus, the removal of impediments to occupational choice provides efficiency and justice simultaneously. 
In addition, by comparing China in the 1980s to China in 2009, we find that the country has made significant progress in reducing the barriers to accumulating human capital and labor market frictions, which leads to labor productivity growth. This result is both good and bad news for China: on one hand, it indicates that in the past two decades, China has been successful in reducing these impediments, while on the other hand, the country must now look for other sources of potential growth moving forward.

\section{Acknowledgements}

I would like to thank Lee Ohanian, Romain Wacziarg, Antonio Bernardo, and Pablo Fajgelbaum for their guidance and support throughout my graduate studies. I would also like to thank Donald Treiman, Kyle Herkenhoff, Miaojie Yu, Changhua Yu, Puyang Sun, Yongjin Wang, Haichao Fan, Jie Cai, and all the other participants of seminars at UCLA, Peking University, Nankai University, Shanghai University of Finance and Economics for their helpful comments. Additionally, I am grateful for Fanghua Li's help in processing data and Amanda Nguyen's help in proofreading. All remaining errors are mine.

\section{Funding}

I thank the support of National Natural Science Foundation of China (Funder Id: 10.13039/501100001809, Grant No. 71703180).

\section{Appendix A}

\section{Detailed model solution}

The individual maximization problem (Equation 5-7) can be solved explicitly:

$$
\begin{gathered}
s_{j}=\frac{1}{1+\frac{1-\eta}{\beta \phi_{j}}} \\
e_{i j}=\left[\delta_{i j}\left(1-\tau_{i j}\right) w_{j} \epsilon_{j} \eta s_{j}^{\phi_{j}}\right]^{\frac{1}{1-\eta}} \\
U_{i j}=\left[\delta_{i j}\left(1-\tau_{i j}\right) w_{j} \epsilon_{j} \eta^{\eta}(1-\eta)^{1-\eta} s_{j}^{\phi}\left(1-s_{j}\right)^{\frac{1-\eta}{\beta}}\right]^{\frac{\beta}{1-\eta}}
\end{gathered}
$$

Based on the solution to the individual maximization problem, we can solve for each element of the transition matrix:

$$
\begin{gathered}
p_{i j}=\frac{\psi_{i j}^{\theta}}{\sum_{k} \psi_{i k}^{\theta}} \\
\psi_{i j}=\delta_{i j}\left(1-\tau_{i j}\right) T_{i j}^{1 / \theta} w_{j} s_{j}^{\phi_{j}}\left(1-s_{j}\right)^{\frac{1-\eta}{\beta}}
\end{gathered}
$$

Given the occupation distribution in the last generation, we can calculate the occupation distribution of the next generation:

$$
\pi_{j}=\sum_{i} \pi_{i}^{L} p_{i j}=\sum_{i} \pi_{i}^{L} \cdot \frac{\psi_{i j}^{\theta}}{\sum_{k} \psi_{i k}^{\theta}}
$$

We also can derive the average quality of workers in each occupation: 


$$
E_{i}\left[h_{i j} \epsilon_{i j} \mid j\right]=\delta_{i j}^{\frac{1}{11-\eta}}\left(1-\tau_{i j}\right)^{\frac{\eta}{1-\eta}}\left(s_{j}^{\phi_{j}} \eta^{\eta}\right)^{\frac{1}{1-\eta}} w_{j}^{\frac{\eta}{1-\eta}}\left(\frac{T_{i j}}{p_{i j}}\right)^{\frac{1}{\theta(1-\eta)}} \cdot \Gamma\left(1-\frac{1}{\theta(1-\eta)}\right)
$$

Combined with Equation (24), we re-write Equation (27) as

$$
E_{i}\left[h_{i j} \epsilon_{j} \mid j\right]=\frac{1}{w_{j}\left(1-\tau_{i j}\right)} \eta^{\frac{1}{1-\eta}}\left(1-s_{j}\right)^{-\frac{1}{\beta}}\left(\sum_{k} \psi_{i k}^{\theta}\right)^{\frac{1}{\theta(1-\eta)}} \cdot \Gamma\left(1-\frac{1}{\theta(1-\eta)}\right)
$$

Therefore, the average income of any given group is

$$
\begin{aligned}
I N C_{i j} & =\left(1-\tau_{i j}\right) w_{j} E_{i}\left[h_{i j} \epsilon_{j} \mid j\right] \\
& =\eta^{\frac{1}{1-\eta}}\left(1-s_{j}\right)^{-\frac{1}{\beta}}\left(\sum_{k} \psi_{i k}^{\theta}\right)^{\frac{1}{\theta(1-\eta)}} \cdot \Gamma\left(1-\frac{1}{\theta(1-\eta)}\right)
\end{aligned}
$$

Based on Equation (29), comparing $I N C_{i j}$ across $i$ and $j$ would generate

$$
\begin{gathered}
\frac{I N C_{i g}}{I N C_{i h}}=\left(\frac{1-s_{g}}{1-s_{h}}\right)^{-\frac{1}{\beta}} \\
\frac{I N C_{k j}}{I N C_{f j}}=\frac{\left(\sum_{m} \psi_{k m}^{\theta}\right)^{\frac{1}{\theta(1-\eta)}}}{\left(\sum_{m} \psi_{f m}^{\theta}\right)^{\frac{1}{\theta(1-\eta)}}}
\end{gathered}
$$

The total amount of the supply of efficiency labor in occupation $j$ can thus be written as

$$
H_{j}=\sum_{i=1}^{M} \pi_{i}^{L} p_{i j} \cdot E_{i}\left[h_{i j} \epsilon_{i j} \mid j\right]
$$

Plugging Equation (28) into Equation (32):

$$
H_{j}=\left(\eta^{\eta} s_{j}^{\phi} w_{j}^{\eta}\right)^{\frac{1}{1-\eta}} \cdot\left\{\sum_{i}\left[\pi_{i}^{L} p_{i j}^{1-\frac{1}{\theta(1-\eta)}} \cdot T_{i j}^{\frac{1}{\theta} \frac{1}{1-\eta}} \cdot\left(\delta_{i k}\left(1-\tau_{i k}\right)^{\eta}\right)^{\frac{1}{1-\eta}}\right]\right\} \cdot \Gamma\left(1-\frac{1}{\theta(1-\eta)}\right)
$$

Define $\Phi_{j}$ :

$$
\Phi_{j}=\left(\eta^{\eta} s_{j}^{\phi}\right)^{\frac{1}{1-\eta}} \cdot\left\{\sum_{i}\left[\pi_{i}^{L} p_{i j}^{1-\frac{1}{\theta(1-\eta)}} \cdot T_{i j}^{\frac{1}{\frac{1}{1}^{1-\eta}}} \cdot\left(\delta_{i k}\left(1-\tau_{i k}\right)^{\eta}\right)^{\frac{1}{1-\eta}}\right]\right\} \cdot \Gamma\left(1-\frac{1}{\theta(1-\eta)}\right) .
$$

As a result, Equation (33) can be simplified as:

$$
H_{i}=\Phi_{i} \cdot w_{i}^{\frac{\eta}{1-\eta}}
$$

From the maximization problem of the representative firm (Equations 10-11), we can solve for the income per unit of efficiency labor:

$$
w_{j}=Y^{\frac{1}{\sigma}} A_{j}^{\frac{\sigma-1}{\sigma}} H_{j}^{-\frac{1}{\sigma}}
$$

Combining Equations (11), (35) and (36) and denoting $\zeta=1+\frac{1}{\sigma} \frac{\eta}{1-\eta}$, we can solve for $H_{j}$ and $w_{j}$ :

$$
H_{j}=\Phi_{j}^{\frac{1}{\zeta}} A_{j}^{\frac{\sigma-1}{\sigma} \frac{\eta}{1-\eta} \frac{1}{\zeta}} Y^{\frac{\eta}{\sigma \zeta(1-\eta)}}
$$




$$
w_{j}=\Phi_{j}^{\frac{1-\zeta}{\zeta} \frac{1-\eta}{\eta}} A_{j}^{\frac{\sigma-1}{\sigma} \frac{1}{\zeta}} Y^{\frac{1}{\sigma \zeta}}
$$

We also can solve for aggregate output Y:

$$
Y=\left\{\sum_{j}\left(A_{j}^{1+\frac{\sigma-1}{\sigma} \frac{\eta}{1-\eta} \frac{1}{\zeta}} \Phi_{j}^{\frac{1}{\zeta}}\right)^{\frac{\sigma-1}{\sigma}}\right\}^{\frac{\sigma}{\sigma-1} \cdot \frac{1}{1-\frac{1}{\sigma} \frac{1}{\zeta} \frac{\eta}{1-\eta}}}
$$

\section{Appendix B}

\section{Altham statistics}

By definition, the Altham statistic $d(P, Q)$ measures the distance between matrices $\mathrm{P}$ and $\mathrm{Q}$ :

$$
d(P, Q)=\left[\sum_{i=1}^{r} \sum_{j=1}^{s} \sum_{l=1}^{r} \sum_{m=1}^{s}\left|\log \left(\frac{p_{i j} p_{l m} q_{i m} q_{l j}}{p_{i m} p_{l j} q_{i j} q_{l m}}\right)\right|^{2}\right]^{\frac{1}{2}}
$$

Define $a_{i j}=\log \left(\frac{p_{i j}}{\bar{q}_{i j}}\right)$. It follows that

$$
\begin{aligned}
d(P, Q)^{2} & =\left[\sum_{i} \sum_{j} \sum_{l} \sum_{m}\left|\log \left(\frac{p_{i j} p_{l m} q_{i m} q_{l j}}{p_{i m} p_{l j} q_{i j} q_{l m}}\right)\right|^{2}\right] \\
& =\sum_{i} \sum_{j} \sum_{l} \sum_{m}\left(a_{i j}+a_{l m}-a_{i m}-a_{l j}\right)^{2} \\
& =4 r s \sum_{i} \sum_{j} a_{i j}^{2}+4\left(\sum_{i} \sum_{j} a_{i j}\right)^{2}-4 r \sum_{i}\left(\sum_{j} a_{i j}\right)^{2}-4 s \sum_{j}\left(\sum_{i} a_{i j}\right)^{2}
\end{aligned}
$$

On the other hand, we know

$$
\begin{aligned}
& 4 r s \cdot \sum_{i} \sum_{j}[a_{i j}-\frac{\sum_{m} \sum_{l} a_{m l}}{\frac{r s}{\text { matrix mean }}}-\underbrace{\left(\frac{\sum_{m} a_{m j}}{r}-\frac{\sum_{m} \sum_{l} a_{m l}}{r s}\right)}_{\text {column deviation }}-\underbrace{\left(\frac{\sum_{l} a_{i l}}{s}-\frac{\sum_{m} \sum_{l} a_{m l}}{r s}\right)}_{\text {row deviation }}]^{2} \\
& =4 r s \cdot \sum_{i} \sum_{j}\left(a_{i j}-\frac{\sum_{m} a_{m j}}{r}-\frac{\sum_{l} a_{i l}}{s}+\frac{\sum_{m} \sum_{l} a_{m l}}{r s}\right)^{2} \\
& =4 r s \cdot \sum_{i} \sum_{j}[\underbrace{\left(a_{i j}-\frac{\sum_{m} a_{m j}}{r}-\frac{\sum_{l} a_{i l}}{s}\right)^{2}}_{\text {term } 1}+\underbrace{\left(\frac{\sum_{m} \sum_{l} a_{m l}}{r s}\right)^{2}}_{\text {term } 2}+\underbrace{2 \cdot\left(a_{i j}-\frac{\sum_{m} a_{m j}}{r}-\frac{\sum_{l} a_{i l}}{s}\right) \cdot \frac{\sum_{m} \sum_{l} a_{m l}}{r s}}_{\text {term } 3}]
\end{aligned}
$$

We can further simplify the three terms in Equation (40) as follows:

$$
\begin{aligned}
\text { term } 1 & =\sum_{i} \sum_{j}\left(a_{i j}-\frac{\sum_{m} a_{m j}}{r}-\frac{\sum_{l} a_{i l}}{s}\right)^{2} \\
& =\sum_{i} \sum_{j}\left(a_{i j}^{2}+\frac{\left(\sum_{m} a_{m j}\right)^{2}}{r^{2}}+\frac{\left(\sum_{l} a_{i l}\right)^{2}}{s^{2}}-2 a_{i j} \cdot \frac{\sum_{m} a_{m j}}{r}-2 a_{i j} \cdot \frac{\sum_{l} a_{i l}}{s}+2 \frac{\sum_{m} a_{m j}}{r} \cdot \frac{\sum_{l} a_{i l}}{s}\right)^{2} \\
& =\sum_{i} \sum_{j} a_{i j}^{2}+\frac{1}{r} \sum_{j}\left(\sum_{i} a_{i j}\right)^{2}+\frac{1}{s} \sum_{i}\left(\sum_{j} a_{i j}\right)^{2}-2 \frac{1}{r} \sum_{j}\left(\sum_{i} a_{i j}\right)^{2}-2 \frac{1}{s} \sum_{i}\left(\sum_{j} a_{i j}\right)^{2}+2 \frac{1}{r s}\left(\sum_{i} \sum_{j} a_{i j}\right)^{2} \\
& =\sum_{i} \sum_{j} a_{i j}^{2}-\frac{1}{r} \sum_{j}\left(\sum_{i} a_{i j}\right)^{2}-\frac{1}{s} \sum_{i}\left(\sum_{j} a_{i j}\right)^{2}+2 \frac{1}{r s}\left(\sum_{i} \sum_{j} a_{i j}\right)^{2}
\end{aligned}
$$




$$
\begin{gathered}
\text { term } 2=\sum_{i} \sum_{j}\left(\frac{\sum_{m} \sum_{l} a_{m l}}{r s}\right)^{2}=\frac{1}{r s}\left(\sum_{i} \sum_{j} a_{i j}\right)^{2} \\
\text { term } 3=\sum_{i} \sum_{j} 2 \cdot\left(a_{i j}-\frac{\sum_{m} a_{m j}}{r}-\frac{\sum_{l} a_{i l}}{s}\right) \cdot \frac{\sum_{m} \sum_{l} a_{m l}}{r s} \\
=\frac{2}{r s} \cdot\left[\left(\sum_{i} \sum_{j} a_{i j}\right)^{2}-\left(\sum_{i} \sum_{j} a_{i j}\right)^{2}-\left(\sum_{i} \sum_{j} a_{i j}\right)^{2}\right] \\
=-\frac{2}{r s}\left(\sum_{i} \sum_{j} a_{i j}\right)^{2}
\end{gathered}
$$

Plugging Equations (41)-(43) back into Equation (40):

$$
\begin{aligned}
& 4 r s \cdot \sum_{i} \sum_{j}[\underbrace{\left(a_{i j}-\frac{\sum_{m} a_{m j}}{r}-\frac{\sum_{l} a_{i l}}{s}\right)^{2}}_{\text {term } 1}+\underbrace{\left.\frac{\sum_{m} \sum_{l} a_{m l}}{r s}\right)^{2}}_{\text {term } 2}+\underbrace{\left.2 \cdot\left(a_{i j}-\frac{\sum_{m} a_{m j}}{r}-\frac{\sum_{l} a_{i l}}{s}\right) \cdot \frac{\sum_{m} \sum_{l} a_{m l}}{r s}\right]}_{\text {term } 3} \\
& =4 r s \cdot\left[\sum_{i} \sum_{j} a_{i j}^{2}-\frac{1}{r} \sum_{j}\left(\sum_{i} a_{i j}\right)^{2}-\frac{1}{s} \sum_{i}\left(\sum_{j} a_{i j}\right)^{2}+2 \frac{1}{r s}\left(\sum_{i} \sum_{j} a_{i j}\right)^{2}+\frac{1}{r s}\left(\sum_{i} \sum_{j} a_{i j}\right)^{2}-\frac{2}{r s}\left(\sum_{i} \sum_{j} a_{i j}\right)^{2}\right] \\
& =4 r s \cdot\left[\sum_{i} \sum_{j} a_{i j}^{2}-\frac{1}{r} \sum_{j}\left(\sum_{i} a_{i j}\right)^{2}-\frac{1}{s} \sum_{i}\left(\sum_{j} a_{i j}\right)^{2}+\frac{1}{r s}\left(\sum_{i} \sum_{j} a_{i j}\right)^{2}\right] \\
& =4 r s \sum_{i} \sum_{j} a_{i j}^{2}+4\left(\sum_{i} \sum_{j} a_{i j}\right)^{2}-4 r \sum_{i}\left(\sum_{j} a_{i j}\right)^{2}-4 s \sum_{j}\left(\sum_{i} a_{i j}\right)^{2}
\end{aligned}
$$

Comparing Equations (37) and (42), we conclude that:

$$
\begin{aligned}
& d(P, Q)^{2} \\
& \quad=4 r s \cdot \sum \sum_{j}[a_{i j}-\underbrace{\frac{\sum_{m} \sum_{l} a_{m l}}{r s}}_{\text {matrix mean }}-\underbrace{\left(\frac{\sum_{m} a_{m j}}{r}-\frac{\sum_{m} \sum_{l} a_{m l}}{r S}\right)}_{\text {column deviation }}-\underbrace{\left(\frac{\sum_{l} a_{i l}}{S}-\frac{\sum_{m} \sum_{l} a_{m l}}{r S}\right)}_{\text {row deviation }}]^{2}
\end{aligned}
$$

\section{Appendix C}

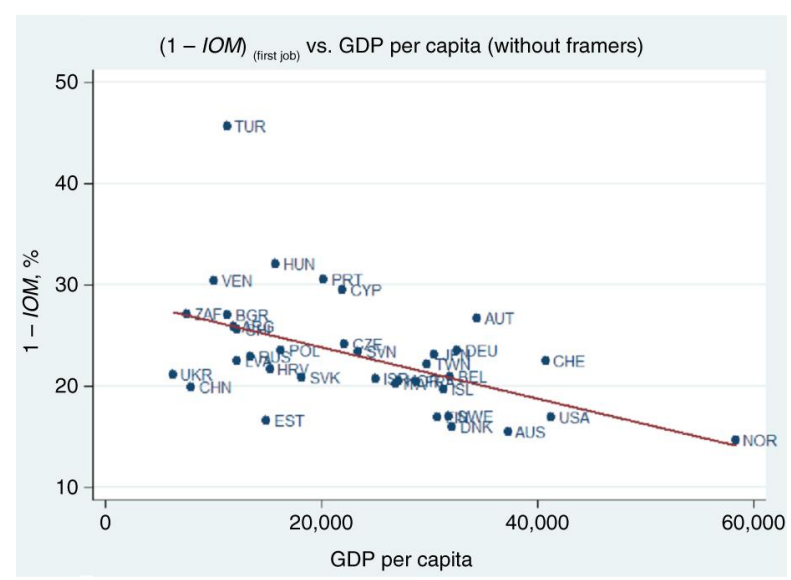

Figure 3: $(1-I O M)_{(\text {first job) }}$ vs. GDP per capita (without farmers). 


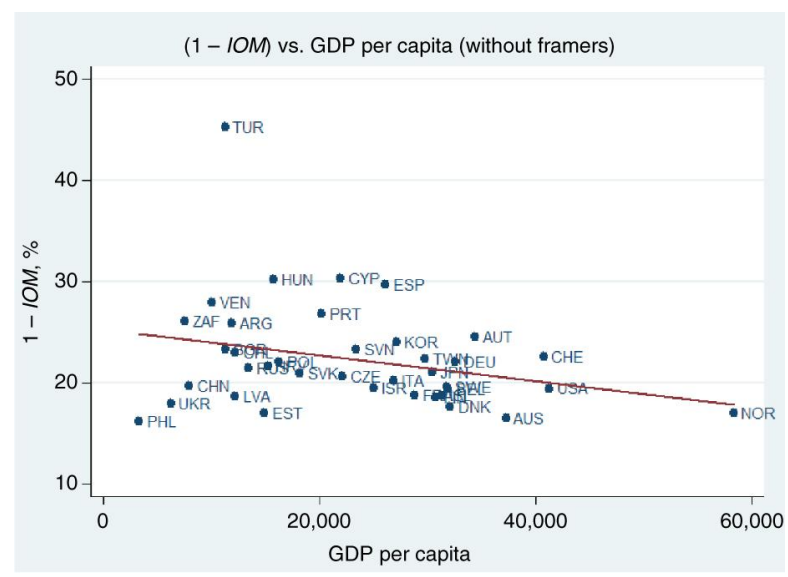

Figure 4: $(1-I O M)$ vs. GDP per capita (without farmers).

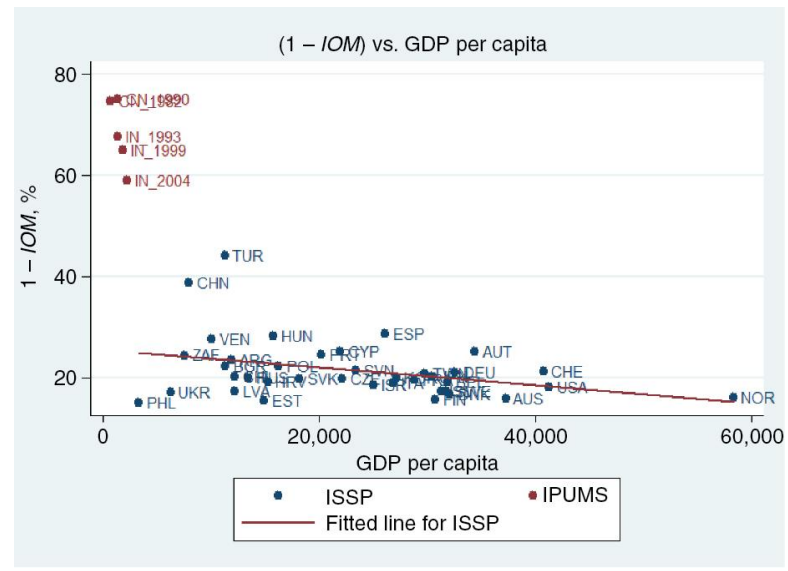

Figure 5: ISSP and IPUMS: $(1-I O M)$ vs. GDP per capita.

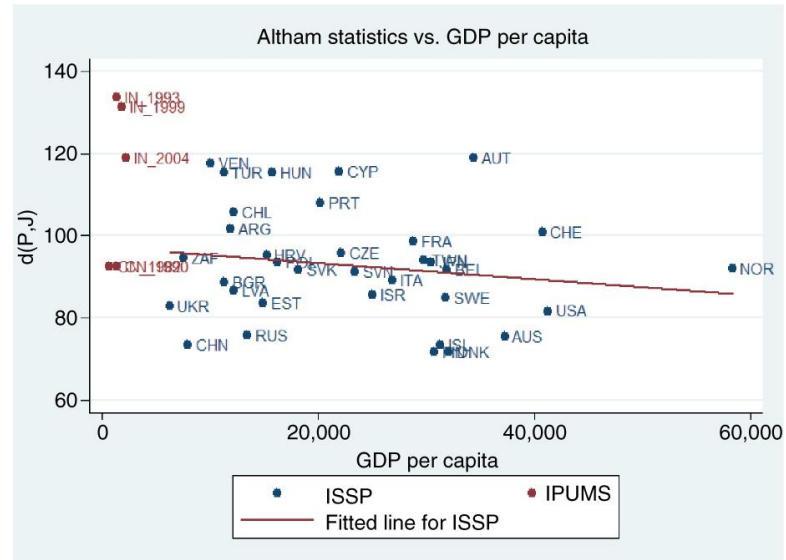

Figure 6: ISSP and IPUMS: altham statistics vs. GDP per capita.

Table 11: ISCO88 1-digit occupations.

\begin{tabular}{lll}
\hline 1-digit Code & Occupation & Skill Level \\
\hline 1 & Legislators, Senior Officials and Managers & 3 \\
2 & Professionals & 4 \\
3 & Technicians and Associate Professionals & 3 \\
4 & Clerks & 2 \\
5 & Service Workers and Shop and Market Sales Workers & 2 \\
6 & Skilled Agricultural and Fishery Workers & 2 \\
7 & Craft and Related Trade Workers & 2
\end{tabular}


*The skill level for occupation 1 is not listed on ISCO official documents. We assign this number based on the skill level for occupations 2 and 3 .

Table 12: US: intergenerational occupational transition matrix.

\begin{tabular}{lrrrrrrrrrr}
\hline & \multicolumn{1}{c}{ Son's Occupation } \\
\cline { 2 - 11 } Father's Occupation & $\mathbf{1}$ & $\mathbf{2}$ & $\mathbf{3}$ & $\mathbf{4}$ & $\mathbf{5}$ & $\mathbf{6}$ & $\mathbf{7}$ & $\mathbf{8}$ & $\mathbf{9}$ \\
\hline 1 & 0.0517 & 0.0546 & 0.0600 & 0.2556 & 0.3202 & 0.0180 & 0.0629 & 0.0643 & 0.1128 \\
2 & 0.0402 & 0.0871 & 0.0780 & 0.2457 & 0.3304 & 0.0210 & 0.0464 & 0.0542 & 0.0972 \\
3 & 0.0396 & 0.0608 & 0.0803 & 0.2585 & 0.3322 & 0.0189 & 0.0537 & 0.0612 & 0.0948 \\
4 & 0.0410 & 0.0543 & 0.0546 & 0.2855 & 0.2977 & 0.0160 & 0.0639 & 0.0798 & 0.1072 \\
5 & 0.0403 & 0.0492 & 0.0518 & 0.2525 & 0.3345 & 0.0172 & 0.0653 & 0.0833 & 0.1058 \\
6 & 0.0248 & 0.0365 & 0.0332 & 0.1670 & 0.2172 & 0.1145 & 0.0729 & 0.0954 & 0.2385 \\
7 & 0.0321 & 0.0373 & 0.0431 & 0.2441 & 0.2966 & 0.0185 & 0.1067 & 0.0969 & 0.1247 \\
8 & 0.0314 & 0.0338 & 0.0390 & 0.2425 & 0.2883 & 0.0179 & 0.0789 & 0.1362 & 0.1318 \\
9 & 0.0301 & 0.0328 & 0.0348 & 0.2209 & 0.2704 & 0.0259 & 0.0760 & 0.1124 & 0.1968 \\
\hline
\end{tabular}

\section{Notes}

1 For example, Breen (2004), Erikson and Goldthorpe (1992), Ganzeboom and Treiman (2007), Grusky and Hauser (1984), Long and Ferrie (2013), Treiman and Ganzeboom (2000), and Treiman and Yip (1989) address this topic, and a section in Blanden (2009) provides a short survey on it. A highly related issue is intergenerational income mobility. Please refer to Solon $(1999,2002)$, Blanden (2009) and Black and Devereux (2011) for reviews.

2 Two exceptions are Behrman, Gaviria, and Miguel (2001) and Reddy (2015). The former addresses intergenerational occupational mobility $(\mathrm{IOM})$ in Latin American countries but classifies occupations only into white-collar and blue-collar categories due to data limitations, while the latter covers India.

3 We will provide detailed information on these measures in later sections.

4 Handicraft makers are a typical example of the former and athletes are an example of the latter.

5 Both papers are independent studies that consider the existence of occupation characteristics in the job market.Our paper differs from Sinha (2014) in the following ways: (1) our paper focuses on talent misallocation in the general sense without emphasizing any particular channel such as credit constraints; (2) our quantitative exercises focus on the comparisons between China/India and the US, and in particular, we compare China before and after the reform and opening-up policy, while Sinha (2014) provides comparisons for more countries but does not include China and does not provide comparisons over time; (3) the two papers use different datasets, and in this paper, we also employ the Altham statistic as a particular measure of IOM; (4) we also provide comparisons between observations based on the first occupation and those based on the current occupation, as determined from our dataset.

6 To be more precise, fieldwork in some countries was carried out in 2008 and 2010. We ignore this small difference in our paper.

7 Due to data limitations, we ultimately end up with 36 countries and territories.

8 http://www.stats.gov.cn/

9 http://www.keepeek.com/Digital-Asset-Management/oecd/education/world-education-indicators-2005/india_wei-2005-9-

en\#.Wjtiz_196po\#page1

10 To be precise, $3.29 \%$ in urban areas and $4.02 \%$ in rural areas.

11 We have implemented robustness checks on $\beta$, and the results suggest that the model is not sensitive to the parameter. This finding is not surprising because a high $\beta$ would benefit the accumulation all occupations, and the heterogeneity of benefits would be limited because individuals would endogenously choose their optimal schooling time. We are happy to provide more information about this robustness check if needed.

\section{References}

Adamopoulos, T., L. Brandt, J. Leight, and D. Restuccia. 2017. “Misallocation, Selection and Productivity: A Quantitative Analysis with Panel Data from China." Technical report, National Bureau of Economic Research.

Awaworyi, S., and V. Mishra. 2014. "Returns to Education in China: A Meta-analysis." Monash Economics Working Papers 41-14, Monash University, Department of Economics.

Barro, R. J., and J. W. Lee. 2013. "A New Data Set of Educational Attainment in the World, 1950-2010." Journal of Development Economics 104: 184-198.

Behrman, J. R., A. Gaviria, and S. Miguel. 2001. “Intergenerational Mobility in Latin America.” Economia 2(1): 1-31.

Bian, Y. 2002. "Chinese Social Stratification and Social Mobility." Annual Review of Sociology 28: 91-116.

Bian, Y., and W. Zhang. 2001. “Economic Regime, Social Networks, and Occupational Mobility.” China Sociology Science 2(10): 77-89. 
Black, S. E., and P. J. Devereux. 2011. "Recent Developments in Intergenerational Mobility." In Handbook of Labor Economics, edited by Orley Ashenfelter, and David Card. North-Holland: Elsevier.

Blanden, J. 2009. "How much can we learn from international comparisons of intergenerational mobility?" CEE discussion papers, CEEDP0111. Centre for the Economics of Education, London School of Economics and Political Science, London, UK.

Breen, R. 2004. Social mobility in Europe. Oxford: Oxford University Press.

Cavalcanti, T., and M. R. D. Santos. 2015. “(Mis)Allocation Effects of an Overpaid Public Sector.” 2015 Meeting Papers 1094, Society for Economic Dynamics.

Chan, K. W., and L. Zhang. 1999. "The Hukou System and Rural-Urban Migration in China: Processes and Changes." The China Quarterly $160:$ $818-855$.

Córdoba, J. C., and M. Ripoll. 2013. “What Explains Schooling Differences Across Countries?” Journal of Monetary Economics 60(2): 184-202.

Cortes, G. M., and G. Gallipoli. 2014. "The Costs of Occupational Mobility: An Aggregate Analysis." Technical report.

Deshpande, A. 2000. “DOes Caste Still Define Disparity? A Look at Inequality in Kerala, India.” American Economic Review 90: 322-325.

Dou, E. 2014. A Neglected Problem in China's Education System. https://blogs.wsj.com/chinarealtime/2014/06/24/a-neglected-problem-inchinas-education-system/.

Eaton, J., and S. Kortum. 2002. “Technology, Geography, and Trade." Econometrica 70(5): 1741-1779.

Erikson, R., and J. H. Coldthorpe. 1992. The Constant Flux: A Study of Class Mobility in Industrial Societies. USA: Oxford University Press.

Erosa, A., T. Koreshkova, and D. Restuccia. 2010. "How Important is Human Capital? A Quantitative Theory Assessment of World Income Inequality." The Review of Economic Studies 77(4): 1421-1449.

Ganzeboom, H. B., and D. J. Treiman. 2007. "Ascription and Achievement in Occupational Attainment in Comparative Perspective." In The Sixth Meeting of the Russell Sage Foundation/Carnegie Corporation.

Cold, T., D. Guthrie, and D. Wank. 2002. Social Connections in China: Institutions, Culture, and the Changing Nature of Cuanxi, Number 21. Cambridge, UK: Cambridge University Press.

Grusky, D. B., and R. M. Hauser. 1984. “Comparative Social Mobility Revisited: Models of Convergence and Divergence in 16 Countries." American Sociological Review 49: 19-38.

Hsieh, C.-T., E. Hurst, C. I. Jones, and P. J. Klenow. 2013. “The Allocation of Talent and US Economic Growth (Version 3.0)." Technical report, National Bureau of Economic Research.

Hsieh, C.-T., E. Hurst, C. I. Jones, and P. J. Klenow. 2016. “The Allocation of Talent and US Economic Growth (Version 4.0).” Technical report, National Bureau of Economic Research.

Hsieh, C.-T., and P. J. Klenow. 2009. "Misallocation and Manufacturing TFP in China and India." The Quarterly Journal of Economics 124(4): $1403-1448$.

International Labour Office. 1990. “ISCO-88: International Standard Classification of Occupations.” Technical report, ILO.

ISSP Research Group. 2009. “International Social Survey Program 2009: Social inequality IV (ISSP 2009)." CESIS Data Archive, Cologne, ZA5400 Data file Version 3.0.0.

Johnson, E. N., and C. C. Chow. 1997. “Rates of Return to Schooling in China.” Pacific Economic Review 2(2): 101-113.

Jung, J. 2014. “Technology, Skill and Growth in a Clobal Economy." THEMA Working Papers 2015-08, THEMA (THéorie Economique, Modélisation et Applications), Université de Cergy-Pontoise.

Karabarbounis, L., and B. Neiman. 2013. “The Global Decline of the Labor Share.” The Quarterly Journal of Economics 129(1): 61-103.

Kuczera, M., and S. Field. 2010. "Learning for Jobs: OECD Reviews of Vocational Education and Training: Options for China.

agakos, D., and M. E. Waugh. 2013. “Selection, Agriculture, and Cross-Country Productivity Differences." The American Economic Review 103(2): 948-980.

Long, J., and J. Ferrie. 2013. "Intergenerational Occupational Mobility in Great Britain and the United States Since 1850." The American Economic Review 103(4): 1109-1137.

Manuelli, R. E., and A. Seshadri. 2014. "Human Capital and the Wealth of Nations." The American Economic Review 104(9): 2736-2762.

Mayer, A. C. 2013. Caste and Kinship in Central India: A Study of Fiji Indian Rural Society. Vol. 1. Londan, UK: Routledge.

Minnesota Population Center. 2014. Integrated Public Use Microdata Series, International: Version 6.3 [Machine-readable database]. Minneapolis: University of Minnesota.

Reddy, A. B. 2015. “Changes in Intergenerational Occupational Mobility in India: Evidence from National Sample Surveys, 1983-2012." World Development 76: 329-343.

Restuccia, D., and R. Rogerson. 2013. “Misallocation and Productivity.” Review of Economic Dynamics 16(1): 1-10.

Restuccia, D., and C. Urrutia. 2004. “Intergenerational Persistence of Earnings: The Role of Early and College Education." American Economic Review 94: 1354-1378.

Roy, A. D. 1951. “Some Thoughts on the Distribution of Earnings.” Oxford Economic Papers 3(2): 135-146.

Sinha, R. 2014. Intergenerational Occupational Mobility and Labor Productivity.

Solon, G. 1999. "Intergenerational Mobility in the Labor Market." Handbook of Labor Economics 3: 1761-1800.

Solon, G. 2002. "Cross-Country Differences in Intergenerational Earnings Mobility." The Journal of Economic Perspectives 16(3): 59-66.

The World Bank. 2007. Skill Development in India: the Vocational Education and Training System. https://openknowledge.worldbank.org/handle/10986/17937.

Treiman, D. J., and H. B. Canzeboom. 2000. "The Fourth Ceneration of Comparative Stratification Research." The International Handbook of Sociology $122-150$.

Treiman, D. J., and K.-B. Yip. 1989. “Educational and Occupational Attainment in 21 Countries," In Cross-National Research In Sociology, edited by Melvin L. Kohn, 373-394. Beverly Hills: Sage Publications.

Zhang, X. 2011. “The Rate of Returns to Schooling: A Case Study of Urban China." Proceedings of the New York State Economics Association 4(1): 137-149. 